\title{
The multifaceted role of connexins in tumor microenvironment initiation and maintaining
}

\author{
Olga M. Kutova ${ }^{1}$, Anton D. Pospelov ${ }^{1}$ and Irina V. Balalaeva ${ }^{1,}$,
}

1 The Institute of Biology and Biomedicine, Lobachevsky State University of Nizhny Novgorod, 23 Gagarin ave., Nizhny Novgorod 603950, Russia; kutovaom@gmail.com (O.M.K.); eso103163@gmail.com (A.D.P.)

\section{* Correspondence: irin-b@mail.ru; Tel.: +7-831-4623-205}

Simple Summary: Connexins are the proteins which comprise gap junctions in the cells. These junctions can directly connect the neighboring cells and the cell interior with the extracellular microenvironment and thus they act as the tissue integrators. Alterations in connexin regulation can lead to unfavorable turn from normal tissue microenvironment to formation of tumor microenvironment. This review tries to examine the role of connexins in orchestrating tumor microenvironment and hence their role in malignancy.

\begin{abstract}
The modern paradigm of studying the processes of carcinogenesis and vital activity of tumor tissues implies increased attention to constituents of tumor microenvironment (TME) and their interactions. These interactions between the cells in TME can be mediated via protein junctions of different types. Connexins (Cnxs) are one of the major contributors to intercellular communication. They form gap junctions responsible for the transfer of ions, metabolites, peptides, miRNA, etc. between neighboring tumor cells as well as between tumor and stromal cells. Cnx hemichannels mediate purinergic signaling and bidirectional molecular transport with the extracellular environment. Additionally, Cnxs were reported to localize in tumor-derived exosomes and facilitate the release of their cargo. A large body of evidence implies that the role of connexins in cancer is multifaceted. Pro- or anti-tumorigenic properties of connexins are determined by their abundance, localization and functionality as well as channel assembly and non-channel functions. In this review we have summarized the data on the Cnxs contribution in TME and to the cancer initiation and progression.
\end{abstract}

Keywords: tumor microenvironment, connexins, cell-cell contacts, tumor stroma, carcinogenesis, tumor development, metastasis

\section{Introduction}

Determination of the mechanisms of carcinogenesis and tumor progression is among the priorities in modern oncology. At the moment the prevailing theory of carcinogenesis is the 'somatic mutation theory' (SMT), which postulates that the malignant phenotype is determined by damage of the cell's DNA, i.e. a mutation which drives the cell to divide uncontrollably. However, accumulating experimental data, especially a cutting-edge research on a tremendous role of microenvironment in tumor progression, reveal the imperfections of this paradigm [1]. An alternative theory, namely 'tissue organization field theory' (TOFT) contemplates that cancer originates as a tissue disease, which is provoked and characterized by a violation of tissue development with the formation of the peculiar tumor microenvironment (TME) [2,3]. TME is a complex and continuously evolving entity which includes immune cells, stromal cells, blood vessels, and non-cellular 
components such as extracellular matrix, exosomes and is characterized by specific physicochemical properties [4]. Thus TOFTs assumes, that mutations are rather the consequence of the adaptation of the cells to the conditions of the 'disturbed order' than a primary cause of cancer [2,3].

In the tissues the direct intercellular communication and cell-matrix communication is maintained through the junctions of various structure and purpose. Intercellular junctions are represented by four types of contacts: tight junctions, which organize into zonula occludens, adherens junctions, which comprise zonula adherens, desmosomes, which are denoted as macula adherens, and gap junctions. These contacts are comprised by a distinct set of integral proteins. Cell adhesion to extracellular matrix (ECM) is also mediated by integral proteins, which are mainly represented by integrins. Different integrin dimers mediate adhesion to various matrix components with different extent of specificity [5]. Tissue integrity and cell polarity are maintained by collective and ordered work of zonula occludens, zonula and macula adherens together with focal adhesion plaques [68]. Highly selective barrier function in the tissues is maintained by tight junctions via strict regulation of paracellular transport [9]. Gap junctions, which are essentially channels, directly connect the cells and mediate rapid communication within the tissue [10].

Gap junction intercellular communication (GJIC) plays the pivotal role in maintaining homeostasis and orchestrating development in a plethora of tissues from cardiac, skeletal and smooth muscles, to glandular epithelium, lens etc. [11-16]. It should also be noted that integral proteins which comprise gap junctions, namely connexins (Cnxs), also possess non-channel related regulative functions in normal and pathological conditions $[17,18]$.

Cnxs were long considered to be tumor suppressors due to their coordinative function when they are assembled into functional channels. Also, non-channel tumor suppressive functions of Cnxs were discovered. At the same time a considerable amount of the opposite evidence is being collected, once again proving that the participation of junction proteins in the cell switch towards malignancy or normalization is highly dependent on the TME $[19,20]$.

In this review, we intend to enlighten the role of Cnxs in the formation of the tumor microenvironment and, therefore, their contribution to processes of carcinogenesis, tumor progression and metastasis.

\section{Connexins - building blocks of gap junctions}

\subsection{General characteristic of connexins and their classification}

Connexins are a family of proteins which form gap junctions in cells of chordate organisms by assembling $\mathrm{Cnx}$ monomers into hexameric hemichannels (connexons), that can function both autonomously, by transmitting signals to the extracellular space; or undergo coupling to form a full-fledged channel that directly connects adjacent cells. Functionally this protein family is similar to channel-forming pannexins and innexins (non-chordate pannexins), though there are only minor sequence similarities between these families. Sequence similarities are limited to the conservatism of specific regions of the molecule, the manner of protein oligomerization and the regulation of channel functions. Still it is hard to tell if these protein families possess a common ancestor $[21,22]$. This may be a result of common evolutionary diversification of protein families, which was achieved via gene duplication and further structural and functional divergence of paralogs [23]. 
Cnxs are represented exclusively in chordates. From the evolutionary perspective they were recently shown to establish well defined subfamilies already in Chondrychtyes; these subfamilies are represented further in higher vertebrates [24]. Classification of Cnxs is based on sequence homology and divides them into 5 subfamilies $(\alpha, \beta, \gamma, \delta, \varepsilon)$ in which proteins possess numbers assigned in the order of their discovery and study. The described principle is mostly used when speaking of $\mathrm{Cnx}$ genes. The most widely used naming of $\mathrm{Cnxs}$ as proteins is based on their predicted molecular weight in kilodaltons (e.g. Cnx 43, Cnx 32, etc.). Different $\mathrm{Cnxs}$ with the same predicted molecular weight are denoted by an additional index (e.g. Cnx 30 and 30.3) [25].

\subsection{Connexin synthesis}

The transcription of $\mathrm{Cnx}$ genes can be initiated by two promoters, which are regulated by both universal and tissue-specific transcription factors. Cnx genes are shown to have one or multiple 5'UTR (Un-Translated Region) exons which are separated from the exon containing the coding sequence by an intron of variable size. In some $\mathrm{Cnx}$ genes, coding sequence may be interrupted by an additional intron. This allows a great variety of alternatively spliced mRNA variants of Cnxs [26]. Among the direct factors that can regulate the synthesis of Cnxs are CAMP, and Wnt (Wingless Int) signaling pathways [27]. Cnxs were reported to be epigenetically regulated by hypermethylation of the promoter or acetylation/deacetilation of histones. For example, the extent and site specificity of $\mathrm{Cnx}$ 26 and 30 methylation were found to correspond with the grade of glioma [28] and Cnx 45 methylation was indicated in colorectal cancer [29].

Cnx translation can be both silenced (via miRNA regulation) or facilitated (on the level of translation initiation via strong internal ribosome entry site (IRES)). IRES can be a reason for truncated forms of Cnxs are translated. It appears that truncated forms of Cnxs play crucial role in Cnx trafficking and functioning [30,31], and can also mediate mitochondrial transport via microtubule organization [32]. Concerning cancer development, truncated Cnxs may facilitate tunneling nanotubes formation which is considered to be a marker of aggressive cancer cells phenotype [33]. Posttranslational modifications of Cnxs are represented by phosphorylation, S-nitrosylation, SUMOylation, ubiquitination, acetylation and lipidation and are thoroughly discussed in recent review [34].

\subsection{Connexin protein structure and its relation to cancer progression}

Cnxs are tetraspan proteins, as they possess 4 transmembrane domains, two extracellular and one intracellular loop, as well as intracellular $\mathrm{N}$ - and C-terminal tails (Fig. $1 \mathrm{~A})$. The most conserved regions of the $\mathrm{Cnx}$ molecule are the extracellular loops, which are responsible for the docking of the Cnxs. They possess consensus patterns with three characteristic cysteines in each loop [35]. These cysteines are not susceptible to posttranslational modification, namely to S-nitrosylation, and what is worth noting, there is an assumption that these cysteines are not responsible for docking solely, but may also act as extracellular redox sensors [36]. The recent review discusses the interplay of redox signaling and Cnxs in normal and pathological conditions [37]. Also, point mutations artificially induced in extracellular loops led to failed docking yet did not affect $\mathrm{Cnx} 43$ tumor suppressive properties thus confirming strong Cnx43 non-channel functions [38]. Transmembrane domains (TM1 to TM4) of Cnxs and amino terminus are also relatively conserved regions. TMs form and maintain the connexon scaffold and the transmembrane pore. Amino terminus of Cnxs is shown to regulate voltage-mediated gating, 
participate in Cnx trafficking, mediate compatibility during heterologous oligomerization [39].

Cnxs variability is mostly provided by the cytoplasmic loop and the C-terminal tail which act as a highly versatile platform for $\mathrm{Cnx}$ regulation and $\mathrm{Cnx}$-mediated signaling. The role of the C-tail of Cnx 43 in its channel and non-channel functioning are well-discussed in comprehensive review by $\mathrm{E}$. Leithe and colleagues [40]. Summarizing the data concerning the role of $\mathrm{Cnx} 43 \mathrm{C}$-tail in cancer phosphorylation status of the C-tail is key as it governs connexin localization on the membrane and the functionality of the assembled channel [41-44]. Phosphorylation can be controlled by interaction with ZO-1 [43]. Indeed, Cnx 43 bears binding sites for signaling kinases Akt and ERK and inhibits the hyperphosphorylation of Akt/ERK which leads to the attenuation of tumor growth in glioblastoma patients [45]. On contrary, it was reported that C-tail mediated inhibition of Src kinase downregulates $\beta$-catenin, triggering the preferential differentiation of neural progenitor cells towards astrocytes (against neurons), and may act as a tumor initiating event in brain tumor [46] as astrocytes are reported to possess pro-tumorigenic activity in glioma microenvironment [47-49]. The polymorphism of the $\mathrm{Cnx} 37 \mathrm{C}$-tail may affect the outcome of its phosphorylation and stimulate the growth of angiosarcoma [50]. Cnx36 Ctail phosphorylation by Ca2+/calmodulin-dependent kinase is reported to decrease its binding affinity to PZD-domain and increase the affinity to proteins 14-3-3y and 14-3-3n [51]. The mentioned proteins of the 14-3-3 family were reported to participate in cancer development [52,53].

The membrane attributed $\beta$-catenin localization and its sequestration from the nucleus is provided by $\mathrm{Cnx} 43$ and is accompanied by the reversal of tumor phenotype in MCF-7 and MDA-MB-231 cells [54]. In rat insulinoma the Cnx37 C-tail conformation, capable to interact both with cell cycle regulatory proteins and pore-forming domain, mediates growth suppression [55]. Mutation in the hDlg (human homologue of Drosophila Discs Large)-binding motif of $\mathrm{Cnx} 43 \mathrm{C}$-tail, induced by human papillomavirus 16 , is reported to disrupt proper Cnx43 and hDlg trafficking to the membrane, so that Cnx 43 remains in the cytoplasm. This is considered to be a tumor initiating event [56].The mutation of Cnx26 C-tail leads to the disruption of its appropriate trafficking due to the acquiring the Golgi-retention sequence. The resulted intracellular $\mathrm{Cnx26}$ accumulation enhances the tumorigenicity of head and neck squamous cell carcinoma cells [57]. Cnx26 C-tail was also reported to directly interact with dynamin 2 which is responsible for Cnx ubiquitination and degradation [58]. The recent review implicates that dynamin 2 is an important contributor to cancer development [59]. Cnx 26 C-tail maintains stemness in triple negative cancer by interaction with NANOG and FAK [60]. 


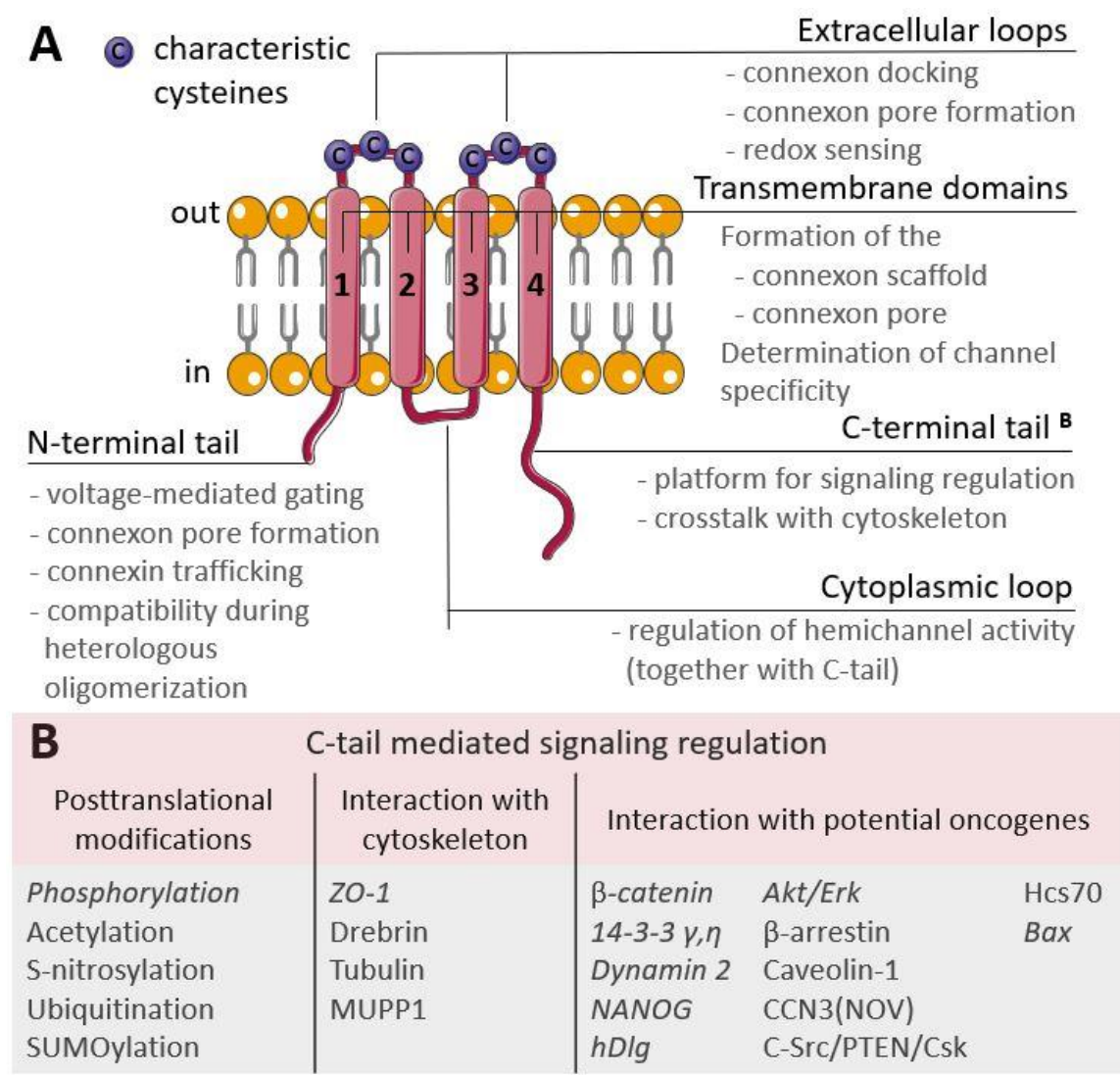

Figure 1. A. The scheme of $\mathrm{Cnx}$ structure. $\mathrm{Cnx}$ is a tetraspan molecule which contains 4 transmembrane a-helices, 2 extracellular loops and 1 cytoplasmic loop; the amino- and carboxy-termini are located in the cell. Transmembrane domains participate in the formation of the connexon scaffold and pore; extracellular loops are responsible for channel docking; the cytoplasmic loop and $\mathrm{N}$ - and $\mathrm{C}$-tails are the platform for the regulation of the $\mathrm{Cnx}$ functioning. $\mathrm{B}$. The participation of the $\mathrm{C}$-tail of $\mathrm{Cnxs}$ in signaling regulation. The reported cancer-related signaling is represented in italic (explanations are in the text).

\section{Connexon assembly, trafficking, localization and function}

\subsection{Connexon assembly and trafficking}

Cnx hexamerization results in the assembly of hemichannel, or connexon. The pore of the connexon allows passage of small substances (up to $1.2 \mathrm{kDa}$ ), in particular ions (Ca2+, $\mathrm{K}+$, bicarbonate), secondary messengers (inositol 3-phosphate, cAMP), Reactive Oxygen Species (ROS), small molecules (glucose, amino acids, nucleotides, ATP, NAD+), peptides and microRNA [20]. Connexon scaffold and pore are formed by transmembrane domains (TMs). It should be noted that the pore entrance has relatively large aperture $\sim 40 \AA$ while it narrows in the membrane to $\sim 15 \AA$ due to tilted domain orientation [61]. According to the early works, the pore formation in connexons was attributed to TM1 or TM3 $[22,62,63]$; further studies indicated that the $\mathrm{N}$-terminus is also involved in the formation of the connexon funnel [64].

Advancements in the methods of structural biology allowed to examine connexon structure with improved precision as it was shown in recent cryo-EM studies. In connexons formed by $\mathrm{Cnx} 46 / 50$, the wide vestibule of the pore from the cytoplasmic side is formed by TM2 and TM3. The membrane embedded part of the pore is maintained by TM1 and TM2 and lined with N-terminal helix which is responsible for in the channel gating. The extracellular part of the pore in the full-fledged gap junction is maintained by extracellular loop 1. The pore contains ordered water molecules both in solventassessable and buried sites which are contemplated to contribute to the regulation of 
channel specificity, conductance and gating [65]. The similar structural features are

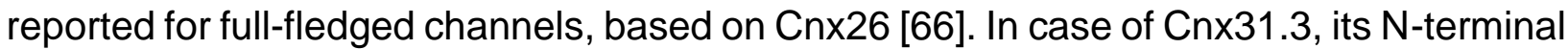
helix is not lining the pore, but is in entrance-covering position and determines the very small pore diameter (8 $\AA$ against 10 and $11 \AA$ in Cnx26 and Cnx46/50 channels

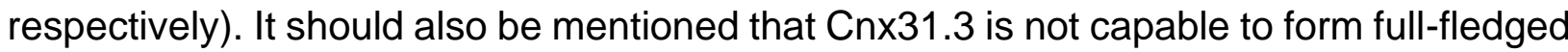
channels and its oligomerization is represented only by hemichannel formation [67]. Taking into account that the composition of the scaffolds of connexons for Cnx31.3 and Cnx26 is nearly identical, this obligate hemichannel state might be attributed to differences in the extracellular loops, affecting the backbone positioning [68].

Cnx oligomerization can occur by two routes which are determined by the signature motif in the region of cytoplasmic loop transition to TM3. The first route is characteristic for alpha-Cnxs: they are stabilized in the monomeric state by quality control proteins and their further oligomerization takes place in the trans-Golgi network. This is determined by a conserved arginine or lysine residue in the cytoplasmic loop-TM3 transition region. The second route is characteristic for beta-Cnxs. They tend to oligomerize rapidly due to the unstable monomeric state, as they possess a signature conserved di-tryptophan motif. There are also $\mathrm{Cnxs}$ which lack signature motif (Cnx37 and $\mathrm{Cnx40)}[69,70]$. The presence of two oligomerization pathways influences the ability of Cnxs to form heteromeric hexamers. Thus, alpha Cnxs tend to heterooligomerize with each other and with Cnxs lacking the conserved motif; beta Cnxs-tend to heterooligomerize exclusively with each other. This process is determined by the expression levels of proteins both in case of alpha- and beta Cnxs, as well as by the extent and timing of the stable monomeric state in case of alpha-Cnxs [71].

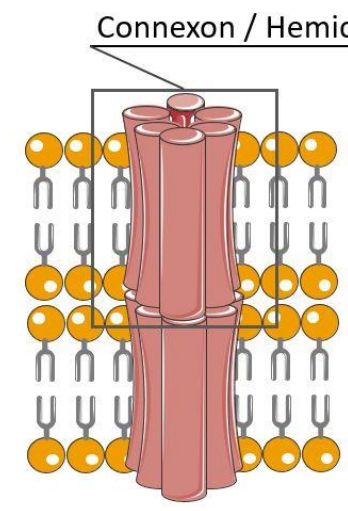

Homomeric connexon Homotypic channel

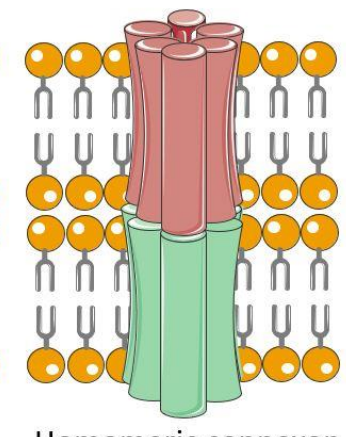

Homomeric connexon Heterotypic channel

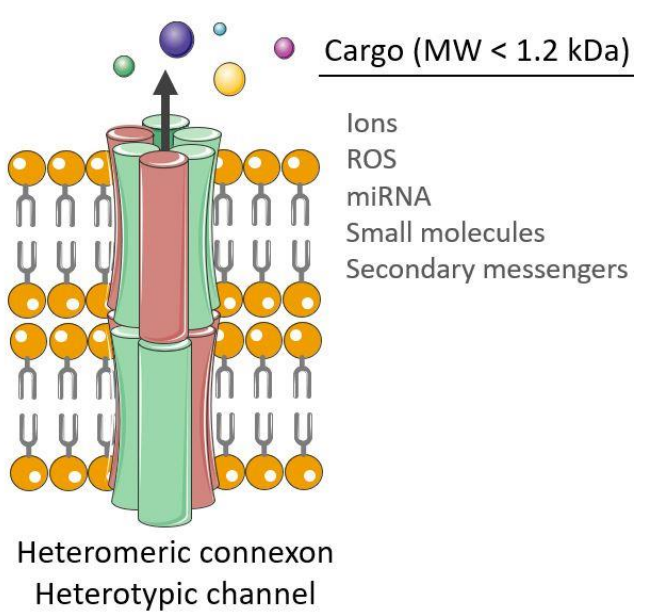

Heterotypic channel

Figure 2. The scheme of connexon and channel assembly. Connexon is a hexamer which is formed with $\mathrm{Cnx}$ monomers and it can be homomeric (constituted of the $\mathrm{Cnx}$ molecules of the same type) or heteromeric (constituted of different Cnxs). Connexons can act as hemichannels and mediate the contact of the cell interior with the extracellular space. Connexons of the neighboring cells can be docked together into the channel which directly connects the adjacent cells. Cnx based channels can be homotypic (connexons are of similar composition) or heterotypic (connexons are of different composition).

\subsection{Connexon localization and function}

Considering Cnx junctions as a factor which directly connects the cells in the TME, the matter of $\mathrm{Cnx}$ localization in the cell is an important issue as it may determine cell behavior. Localization of Cnxs on the cell membrane can be considered in terms of their attribution to certain membrane domains, cell polarity and cell surface protrusions. Cnxs 
can also be localized intracellularly and be membrane-associated (in mitochondria) or be represented in soluble form. A special case of localization of membrane-associated Cnxs is in exosomes (Fig. 3).

\subsubsection{Attribution to the cell membrane domains}

Cnx localization is associated with cholesterol and sphingolipids in the lipid rafts [72]. The Cnx channels usually assemble in gap junction plaques. These plaques may be intersected by junctional proteins of other types both integral and adapter thus establishing a cross-talk of different types of junctions. Gap junction plaques can be intersected by strands of tight junctions and connected to PZD domains of zonula occludens-1 protein (ZO-1). ZO-1 localization on the periphery of the plaque regulates the plaque size and localization [73]. Proteins of cadherin family can also regulate gap junction assembly. Thus, $\mathrm{N}$-cadherin expression in non-transformed rat liver epithelial cells attenuates $\mathrm{Cnx} 43$ gap junction assembly by causing its internalization via clathrinindependent pathway, while E-cadherin mediates the opposite [74]. Analogously, in human squamous carcinoma, E-cadherin was reported to delay the disassembly of Cnx43-based gap junctions [75].

\subsubsection{Attribution to cell polarity}

In normal epithelium, gap junctions tend to possess apicolateral localization in case of thyroid gland and in luminal cells of breast $[76,77]$ or basolateral localization in renal epithelium [78]. Connexins are reported to maintain cell polarity [79]. Gap junctions are involved in apical extrusion of transformed or apoptotic cells from the epithelium as they propagate calcium wave which is followed by the reorganization of F-actin and its perinuclear localization [80].

\subsubsection{Attribution to cell surface protrusions}

Connexin localization may be attributed to the tip areas of cell surface protrusions (e.g. tunneling nanotubes, TNTs). Tunneling nanotubes are thin cell surface protrusions with actin core. Their length can reach several cell diameters, and the diameter of TNTs does not exceed $1 \mu \mathrm{m}$. TNTs allow direct connection of distantly located cells within the tissue and thus are involved in the coordination of communication in the tissue and the development of cell resistance to necrosis and apoptosis [81-83]. Connexins are reported participate in the regulation of TNTs formation. Loss of Cnx43 expression is associated with a significant decrease in the length and amount of TNT in breast cancer cell lines [33]. In line, secreted factors present in the conditioned medium stimulated TNT formation more effectively when derived from Cnx43 expressing cells than from knockout cells. Moreover, Cnx43 is involved in crosstalk with RhoA kinase (ROCK), protein kinase A (PKA), focal adhesion kinase (FAK) and p38 signaling pathways. It was reported that inhibition of these pathways can induce TNT formation [33]. Cnx43 can also promote the formation of filopodia in HeLa cells by remodeling the actin cytoskeleton via activation of p21-activated protein kinase 1 and MAPK p38 pathway $[84,85]$. In MCF-7 breast cancer cells TNTs were reported to be an important means of spheroid formation in low-adhesive conditions in vitro. At its early stages TNTs have enabled physical adhesion in the suspended cells establishing Cnx43 contacts with further E-cadherin expression [86]. Thus, TNTs can be considered as an integrating factor in the tumor tissue.

\subsubsection{Intracellular localization of connexins}


Connexins can also be localized on intracellular compartments, namely on mitochondria. Full-fledged versions of connexin are found in mitochondria of a wide variety of cells, including cardiomyocytes, endothelium, astrocytes [87-89]. Mitochondria cannot synthesize connexin on their own and integrate it into the inner membrane from the cytoplasm of the cell through the heat shock protein (HSP)90-dependent translocase of the outer membrane (TOM20) complex pathway [90]. HSP90-dependent translocation of Cnx30 to mitochondria observed after irradiation was shown to induce enhanced ATP production and protect glioblastoma cells from radiation treatment [91].

One of the main signs of transformed cells is changes in metabolism and death pathways, in which mitochondria occupy a central position. It is known that tumors tend to develop conditions similar to ischemia under chronic hypoxia. A possible way of reducing mitochondrial ROS production in such a conditions depends on an increase in the phosphorylation of $\mathrm{Cnx} 43$, which accelerates its translocation into mitochondria [92]. Moreover, $\mathrm{Cnx} 43$ can modulate the release of cytochrome $\mathrm{c}$ and the activation of caspase 3 , thereby providing an anti-apoptotic effect and increasing resistance to toxins, chemotherapeutic drugs, or ionizing radiation [93]. Also, the anti-apoptotic role of mitochondrial $\mathrm{Cnx} 43$ is mediated by the conserved motif in $\mathrm{Cnx} 43$ structure homologous to the protein of Bcl-2 group which controls the cytochrome c release [94]. Despite the assumptions made about an increase in cell resistance to hypoxia due to mitochondrial connexin, a number of works suggest that $\mathrm{Cnx} 43$ is involved in mitochondrial respiration, which increases oxygen consumption. The authors suggest that an increase in the expression of mitochondrial connexin shifts cellular metabolism from anaerobic glycolysis towards oxidative phosphorylation which is associated with the increased sensitivity of cells to oxidative stress $[95,96]$.

Cnx relocalization can be triggered by an external factor. Cnxs possess voltage mediated gating, so they can be susceptible to the changes in electromagnetic field. A number of early fundamental works showed that the organization of gap junction plaques can be influenced by a low-frequency electromagnetic field (LF EMF) [97-100]. It was shown that Cnx43 undergoes internalization under cells treatment with LF EMF and localizes in perinuclear region of cytoplasm. The same effect was observed under the Cnx hyperphosphorylation by GJIC inhibitor 12-O-tetradecanoylphorbol-3-acetate (TPA). Indeed protein kinase C (PKC) inhibition by staurosporine significantly reduced GJIC downregulation mediated by LF EMF [97]. In addition to phosphorylation Cnx regulation by LF EMF proceeds at the transcriptional level, as was shown that long-term exposure has reduced mRNA levels of $\mathrm{Cnx} 43$ [98]. Although the experimental evidence that the LF EMF impact on connexin relocalization exists, it is not limited to it solely. It can GJIC solely not affecting $\mathrm{Cnx} 43$ levels [99] or even stimulates $\mathrm{Cnx} 43$ synthesis and proper gap junction assembly [100]. The role of intracellular localization of Cxs is generally associated with tumor progression $[57,101,102]$, but this issue is still to be studied. 


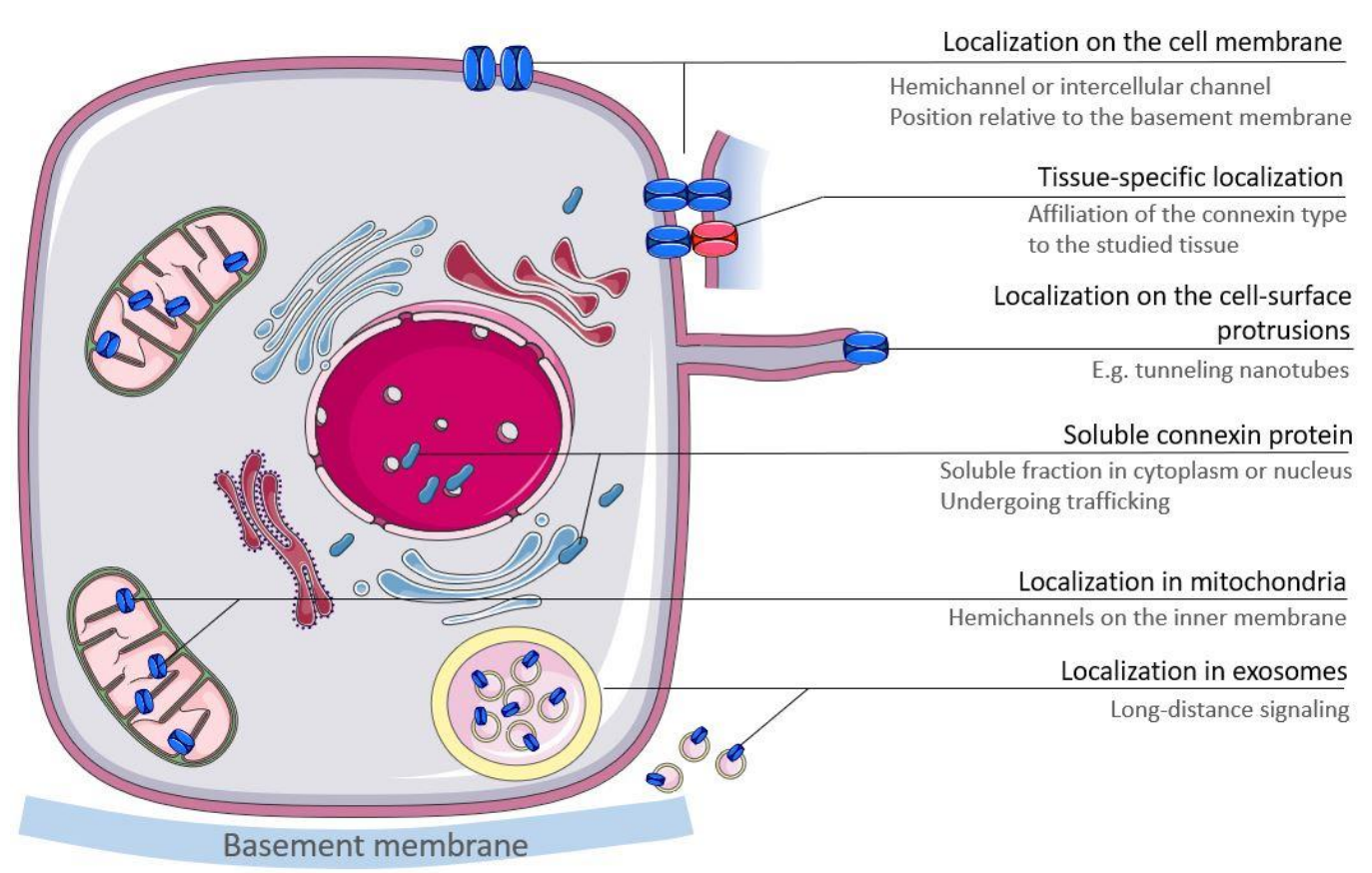

Figure 3. Possible localization of Cnxs in the cell. The localization of Cnxs in the cell can be attributed to its soluble forms (located in the nucleus or cytoplasm) or membrane bound forms which can be observed during its trafficking and ultimately represented as functional connexon resided in the cell membrane in the state of hemichannel or channel (when docked to the connexon of the neighboring cell). The localization of Cnx channels on the membrane can be considered relatively to the localization to the basal membrane (cell polarity) or attributed to the cell protrusions (e.g. tunneling nanotubes) or extracellular vesicles (e.g. exosomes). Connexons can be also transferred into the inner membrane of mitochondria. An important issue is the affiliation of the Cnx type to the tissue.

\subsubsection{Connexin localization in exosomes}

Exosomes are extracellular lipid bilayer vesicles with average size of $100 \mathrm{~nm}$ which are produced by most eukaryotic cells and which carry a bioactive cargo of various nature (protein, lipids, miRNA etc.). Tumor-derived exosomes one of the major contributors to TME and they long distance signaling in cancer. [103,104]. Connexins were indicated to localize in exosomes, and be associated (i.e. colocalized) with exosomal characteristic proteins tetraspanins [105]. Exosomal connexins can facilitate the release of the exosome contents into the recipient cell and thus enchance malignant potential as was shown for Cnx43 [106,107], and Cnx46 [105]. Exosomal Cnx43 facilitated colony formation and enhanced migration, determining the progression of glioma [107]. Analogously it was shown that the recipient cells which have encountered with Cnx46 exosomes acquired enhanced invasive and migrative phenotype [105].

Connexins may determine the mechanism of the of exosome loading with RNA and DNA. Using bioinformatics analysis, it has been suggested that $\mathrm{Cnx} 43$ and $\mathrm{Cn} \times 26$ possess RNA and DNA-binding motifs, and it may be important for the transmission of genetic information between cells through extracellular vesicles [108].

\subsubsection{Connexon hemichannel functioning}

Connexon functioning as hemichannel has a separate contribution to TME and the development of cancer. Hemichannels can participate in the uptake of beneficial molecules (glucose, survival factors) or provide uptake of glutamate, which promote cell survival under nutrient deficiency [109]. Hemichannel-dependent purinergic signaling loop regulates leader cell activity and subsequent collective migration in breast cancer 
[110]. In addition, connexin hemichannel purinergic signaling is responsible for activating the expression of pro-apoptotic genes in glioblastoma [111] and melanoma [112]; and hemichannel ATP release by osteocytes inhibited breast cancer cell metastasis to the bone [113].

\section{Connexins as contributors to tissue integration}

Considering cancer as a wrongly developed tissue, the coordinative work of the elements of the TME is of particular interest. We here intend to focus on the coordinative features of Cnxs in awry tissue context, from the perspective of functional and morphological aspects of the organization of the cells in tumor tissue. Connexin channels are the direct bridges between neighboring cells, thus the presence of functional gap junctional plaques allows to consider a network of such cells as a functional "syncytium" somewhat similar to cardiac tissue [114]. Formation of such a structure provides metabolic cooperation and a platform for rapid signaling, both are applicable to adapt to limitations of cancer microenvironment. For example, such cooperation can rapidly regulate cell sizes in the actively proliferating tumor. Cells of deep layers of the tumor experience great solid stress, their size is limited, so the water is transported to the cells of the outer layers and is accompanied by the ion transport which proceeds through gap junctions. This causes the swelling of the cells of the outer layers leading to increased cell proliferation [115]. TNTs may be involved in the process of cytoplasmic sharing which can be considered a additional evidence of syncytium-like cancer functioning [116].

These examples of Cnxs participation in the formation of functional syncytium-like network in cancer may be expanded. Cnxs are reported to establish interactions between tumor cells and physiological structural syncytium, e.g. osteoclast syncytium, where they act as tumor promoters facilitating metastasis. In osteoblast conditioned microenvironment, Cnx43 localized on the membrane mediates tumor cell chemotaxis via its non-channel functions. At the leading edge of migrating cells, $\mathrm{Cnx} 43 \mathrm{C}$-tail interacts with Rac1 and contractin thus sustaining cell migration towards the osteogenic metastatic niche [117]. The direct interaction of cancer cells with osteoblasts through $\mathrm{Cnx43-based}$ gap junctions provides a $\mathrm{Ca} 2+$ influx to cancer cells enhancing their malignant potential [118]. By interacting with osteoclast syncytium, cancer cells promote bone resorption during which a massive release of calcium and transforming growth factor-beta (TGF $\beta$ ) takes place. TGF $\beta$ upregulates $\mathrm{Cnx43}$, thus elevating intracellular concentrations of calcium and enhancing GJIC; in turn, $\mathrm{Cn \times 43}$ accelerates metastasis in the framework of this vicious cycle [119]. Taken together, the participation of connexin in bone metastasis may be considered as two-stage process with the connexin C-tail mediated attraction of cancer cells and channel-related progression.

The material summarized above discusses the functional aspect of the tissue consolidation to the syncytium-like structure. It must be also noted that cancer tissues are capable of establishing the structural syncytium - large cell-like structure formed by the joining together of two or more cells. It implies direct fusion of cancer cells with each other or with stromal cells $[120,121]$. Cell fusion phenomenon in cancer is mostly considered as one of the mechanisms contributing to cancer heterogeneity formation stemming from creation of different hybrid cells which, in turn, give rise to various cell populations [122] or act as active metastatic units ( the latter was shown for cancer cell fusion with leukocytes) [123]. Interestingly, aberrant fusion of initially normal cells can act as cancer initiating event through the establishment of genomic instability [124,125]. The 
participation of Cnxs in the formation of structural syncytium is studied mainly for normal physiologic processes, e.g., for the trophoblast formation [126,127]. The contemplated mechanism of this process lies in their cooperation with fusogens such as syncytin. For example, in choriocarcinoma cell fusion is initiated after cAMP stimulation of cells, which upregulate $\mathrm{Cnx} 43$ on the mRNA level providing syncytin transcription by interacting with GCM1-ERVW-1-SLC1A5 pathway [128]. Another example of such cooperation is the functional compensatory substitution of syncytin-B by connexin 30 as shown in syncytinB-null mice [129].

Another aspect of the integrative functions of connexins in TME is their contribution to the communication of the tumor cells and cells of immune system. Connexins participate in the immunological synapse [130] and execute both pro-and antitumor activity [131].

Cnx43 was shown to accumulate at the interfaces between dendritic cells (DC) and cytotoxic immune cells, such as natural killers and cytotoxic T-lymphocytes, and between cytotoxic immune cells and target cells. These interactions are the key in the activation and the execution of the cytotoxic functions towards tumor cells [132-135]. The DCmediated tumor antigen presentation can be enhanced by the bacterial infection via the establishment of functional $\mathrm{Cnx} 43$ contacts between infected cancer cell and DC, as was reported for murine melanoma cells infected with Salmonella [136]. The cytotoxic effect can be also provoked towards stromal cells, e.g. endothelial cells. In 3D collagen cultures, the transfer of peptides across gap junctions between melanoma cells and endothelial cells causes the destruction of endotheliocytes by cytotoxic $T$ cells [137]. Likewise, at immunological synapses between DC and T cells, the Cnx43 hemichannels are involved in the release of ATP and the induction of purinergic receptor signaling, which promotes T-cell activation, proliferation, and clonal expansion [138].

Cnx contact between tumor cells and immune cells are reported to mediate protumorigenic effect. It was found that c-MYC (cellular Myelocytomatosis, a protooncogene) mediated elevation of $\mathrm{Cnx} 43$ contact between cancer cells and astrocytes facilitates breast cancer metastasis to the brain [139]. Cnx43 participates in the fusion of osteoclasts and monocytes in the microenvironment of giant-cell tumor of bone. This abnormal cellular cooperation is most likely associated with an attempt by monocytes to regenerate the cancer-associated damage to the bone tissue, which instead leads to an increase in the size of the tumor [140]. Cnx contacts between tumor cells also mediate the escape of immune surveillance. In melanoma, hypoxic melanoma cells transfer miR192-5p to DC and tumor-associated T-lymphocytes via Cnx40-based contacts suppressing cytotoxic activity of T-lymphocytes and thus provoking the development of an immune-resistant tumor phenotype [141]. Another way to escape immune surveillance can be implemented through the disruption of immunological synapse between melanoma cell and natural killers. It has been shown that hypoxia-induced overexpression of $\mathrm{Cnx43}$ in melanoma cells is associated with formation of functional channels which were even are properly localized at the site of the immunological synapse with natural killer cells, but the autophagy prevented Cnx 43 to establish functional synapse, which was phenomenologically shown by colocalization of Cnx 43 and LC3+ autophagosomes [142].

\section{Connexins and cancer initiation}

Early studies in connexin-deficient mice revealed their increased susceptibility to carcinogens[143-146]. This phenomenological coincidence strongly indicated that 
connexins are involved in cancer initiation. Indeed, $\mathrm{Cn} \times 43$ knockout mice tended to be statistically more predisposed to develop lung cancer induced by urethane or DMBA (7,12-Dimethylbenz[a]anthracene) than the wild type mice [143,144]. Cnx32-deficient mice had an increased incidence of liver tumors after exposure to chemical carcinogens (DEN, diethylnitrosamine) and radiation (X-rays), with higher number and sizes of tumor nodes compared to wild-type mice [145,146].

Further investigation of participation of connexins in the processes of tissue transformation induced by an external factor and its switch to malignancy revealed that it can be mediated both by connexins' channel and non-channel functions. For example, the well-known carcinogenic bacterium $\mathrm{H}$. pylori can affect connexins $26,32,37,43$ by triggering various signaling pathways (p38 MAPK, JAK2/STAT3) or through epigenetic action on DNA (methylation of promoters, acetylation of histones) thus regulating expression levels of these molecules, governing their localization or creating their polymorphism [147,148]. Parasitic invasion can also induce malignancy with the decisive participation of connexins. It was reported that transformation of the epithelium of the bile ducts with the eventual cancer development can be provoked by the metabolites of the Clonorchis sinensis. The turning point in this process is the simultaneous decrease in the expression of $\mathrm{Cnx} 32$ and upregulating of $\mathrm{Cnx} 43$ and $\mathrm{Cnx} 26$. Cnx43 in this case is acting as a tumor promoter as its inhibition leads to proliferation decrease [149]. Similarly, nonalcoholic hepatosteatosis can be accompanied by downregulated expression of $\mathrm{Cnx} 32$ which eventually causes liver fibrosis and is followed by hepatocellular carcinoma [150]. The altered expression and functionality of $\mathrm{Cnx43}$ and $\mathrm{Cnx32}$ in oval cells in liver is demonstrated to cause the hepatocellular and cholangiocellular neoplasms due to the disruption of the adequate cell differentiation[151]. Another example is malignant transformation of the intestinal epithelium induced by improper diet and related metabolic stress. In this case activation of PPARD occurs followed by activation of beta catenin signaling which eventually leads to the proinvasive elevation of connexin 43 level [152].

Thus, overexpression of Cnx32 in normal breast epithelium cell line MCF10A decreased cell viability, turned cell morphology towards mesenchymal phenotype and increased migratory activity of the cells with no changes in their proliferative activity [153]. This signs of epithelial-mesenchymal transition (EMT) were accompanied by simultaneous elevation of protein levels of E-cadherin and vimentin, and of note, $\mathrm{Cnx} 32$ overexpression, obtained by lentiviral transfection, directly promoted E-cadherin level elevation. On the contrary, Cnx32 overexpression in malignant breast cell line MDA-MB-231 did not alter viability, proliferation rate or migration activity, however, altered the ratio of EMT markers: along with the persistent high expression of vimentin and slug, the expression of E-cadherin decreased. This indicates that $\mathrm{Cnx} 32$ overexpression may act as a transformationpromoting event which introduces the element of motility to normal tissue [153]. Another example of the morphogenic field disturbance due to the induction of cell motility was reported for healthy skin and heart tissue subjected to injury under hypoxic conditions. In this case, phosphorylation of connexins by Akt-kinase resulted in the sharp increase in the number of gap junctions which interfere with the interaction of connexin with ZO-1, leading to migration of keratinocyte epithelial cells [154].

Considering non-channel role of connexins in tuning the microenvironment, their intracellular signaling through C-tail, discussed in paragraph 2.3., provide a number of ways influencing cancer initiation $[46,56]$. Another example of non-channel connexindependent carcinogenesis is supposed to be associated with de novo expression of 
Cnx46 in breast epithelium is necessary to protect cells from hypoxia which was phenomenologically demonstrated using xenograft models in vivo. Expression of Cnx46 is not detected in normal breast epithelium and is detected in an early breast cancer, thus, it is assumed by the authors that $\mathrm{Cnx}$ expression is a cancer initiation event [155]. Similarly de novo expression of $\mathrm{Cnx} 26$ and $\mathrm{Cnx} 30$ was observed in the epidermal cells of the melanoma microenvironment and was not detected in the microenvironment of benign lesions [156].

The data on contemplated carcinogenic events mediated by connexins are summarized in Table 1. Apparently, the tumor initiating event, or, to be more precise, a complex of conditions in the site of tumor initiation, make a switch towards the decrease of the connexins immanent to the tissue and elevation of connexins which are normally foreign to it. This might be one of the crucial factors in the turn towards TME. It is still to be investigated, why the expression of the foreign connexin is more suitable for new conditions; and what is the ratio of channel related role and non-channel functions of these foreign connexins. The obtained data in this respect is mainly phenomenological and mechanistic explanation how the switch in $\mathrm{Cnx}$ profile promotes malignant transformation is the matter for future research.

Table 1. A summary of contemplated carcinogenic events mediated by connexins

\begin{tabular}{|c|c|c|c|}
\hline Connexin & Cell type & Initiation trigger & References \\
\hline Cnx32 & $\begin{array}{l}\text { Gastric epithelial cells } \\
\text { GES-1 }\end{array}$ & $\begin{array}{l}\text { H. pylori infection increase GATA-3 } \\
\text { expression and decreased Cnx32 } \\
\text { expression }\end{array}$ & [147] \\
\hline Cnx32 & $\begin{array}{l}\text { Metastatic breast cancer cells MDA- } \\
\text { MB-231 }\end{array}$ & $\begin{array}{l}\text { Cnx32 overexpression decrease the mRNA } \\
\text { and protein expression of E-cadherin while } \\
\text { increasing vimentin and slug at mRNA levels } \\
\text { without altering their protein expression }\end{array}$ & [153] \\
\hline Cnx32 & Rat hepatocytes & $\begin{array}{c}\text { Combination of a high-fat diet and } \\
\text { dimethylnitrosamine decrease } \mathrm{Cn} \times 32 \\
\text { expression }\end{array}$ & [150] \\
\hline Cnx43 & $\begin{array}{c}\text { Colon Adenocarcinoma SW480, } \\
\text { SW620, CT26, HCT116 }\end{array}$ & $\begin{array}{c}\beta \text {-catenin activation of PPAR-delta leads to } \\
\text { upregulation of } \mathrm{Cnx43}\end{array}$ & [152] \\
\hline Cnx43 & Rat neural progenitor cells & $\begin{array}{l}\text { TAT-Cx43266-283 (cell-penetrating peptide } \\
\text { containing the sequence } 266-283 \text { of the } \\
\text { Cnx } 43 \text { C-tail) inhibit Src activity }\end{array}$ & {$[46]$} \\
\hline Cnx43 & Glioma cells GL261 & Genetical upregulation of $\mathrm{Cnx} 43$ & [48] \\
\hline Cnx43 & Cholangiocyte cells $\mathrm{H} 69$ & $\begin{array}{c}\text { Cnx43 is upregulated by } \mathrm{N} \text { - } \\
\text { nitrosodimethylamine secreted by } \\
\text { Clonorchis sinensis }\end{array}$ & {$[149]$} \\
\hline Cnx46 & Human breast cancer cells MCF-7 & $\begin{array}{c}\text { Hypoxia induces upregulation of } \mathrm{Cnx} 46 \\
\text { expression }\end{array}$ & {$[155]$} \\
\hline
\end{tabular}

\section{Connexins in cancer progression and metastasis}

TME can maintain processes of tumor progression, invasion, and metastasis and can also determine tumor resistance to treatment. Further we consider the participation of Cnxs in the specific aspects of TME such as its physicochemical features and cancer stemness.

\subsection{Hypoxia, acidosis and interstitial fluid pressure}


Hypoxia is a biological condition characterized by insufficient oxygenation of tissues which, in case of malignant tumors, is caused by rapid cell proliferation $[157,158]$. The oxygenation levels in tumors are lower compared to normal tissues. For example, it was demonstrated with polarography method, that oxygenation levels in well-oxygenated tissues, such as muscle, lies in the range of 20 and $70 \mathrm{mmHg}$, while in breast tumor it ranges between 3 to $30 \mathrm{mmHg}$, which indicates hypoxic characteristics [159].

Hypoxic conditions are, on the one hand, a circumstance that is destructive for tumor cells, which cells must cope with, and on the other hand, a powerful selection factor for their collective adaptation with the subsequent development of progression mechanisms. One of the characteristics of severely hypoxic microenvironment is acidosis, and functional GJIC mediated by connexins allow to manage it. Thus, in spheroids of pancreatic cancer, it has been shown that connexin channels between hypoxic and normoxic cells allow rapid distribution of bicarbonate ions to neutralize acidification in hypoxic areas [160]. The transfer of ions occurs passively, which is energetically beneficial for hypoxic cells, as they retain ATP. More than that, the tumors can protect themselves from acidification by another mechanism, specifically, transmitting lactate through Cnx43-based channels [161].

It has been shown that acidosis management can be also carried out with the participation of the stroma. Hydrogen ions, produced by tumor cells are captured from the extracellular space by the AE2 transporter on myofibroblasts and are then spread via Cnx43 channels through the myofibrblast syncytium. [162]. At the same time, severe acidosis along with high calcium concentrations lead to the closure of connexin channels and their uncoupling and interruption of the GJIC in rat hepatocellular carcinoma and human glioblastoma A172 [163].

Overcoming hypoxia on a large scale is realized in tumors by promoting angiogenesis. In high-grade serous ovarian cancer, endothelial cells are characterized by elevated level of HIF1a (Hypoxia-Induced Factor 1 alpha), while the level of $\mathrm{Cnx} 43$ reduces and its localization on the membranes of endotheliocytes is patchy indicating loss of adequate GJIC and hence the increased permeability of the existing vessel [164] which is reported to be the factor stimulating angiogenesis [165]. At the same time, Cnx43 level in smooth muscle cells was increased [164]. The interaction between smooth muscle cells and dysfunctional endothelium testifies for their switch from contractile to synthetic phenotype, associated with greater angiogenic potential due to enhanced proliferative and migrative potential [166]. It has been shown that endothelial cells grow together with tumor cells in pre-hypoxic areas (micrometastases) and trigger vascularization upon the onset of hypoxic conditions. This phenomenon may be associated with the collective migration of tumor cells that have formed $\mathrm{Cnx} 43$-based contacts with endothelial cells [167]. In melanoma, Cnx43 was reported to promote ubiquitination and degradation of the HIF1a protein in hypoxic conditions, which results in the suppression of tumor angiogenesis [168]. Transcriptional suppression of $\mathrm{Cnx} 43$ and Cnx26 in MDA-MB-231 breast cancer cells led to the downregulation of GJIC between cancer cells and cancer cells-endotheliocytes and was accompanied by reduced migrative and invasive properties as shown by real-time cell analysis [169].

Tumor cells can recruit connexins in favor of tumor progression in hypoxic conditions by triggering EMT. Thus, hypoxic conditions in non-small cell lung cancer trigger the P53/MDM2 pathway and contribute to a decrease in the abundance of Cnx26 and Cnx43 
due to their ubiquitination-mediated degradation and translocation into the cytoplasm. This resulted in reduction of E-cadherin level and an increase in $\mathrm{N}$-cadherin level, the common event in EMT [101]. Connexin translocation into cytoplasm is reported to be associated with the enhancement of malignant phenotype [102,170,171].

Another hypoxia-induced cancer progression mechanism, mediated by Cnxs, is the escaping of the immune surveillance is (discussed in p. 4). Considering the accumulated experimental data, further investigation of the role of Cnxs in tumors their abundance, localization and function should be examined in tumor cells and stromal cells simultaneously. The recent paper by $M$. Navarette provides a comprehensive flow cytometry technique to evaluate gap junction-mediated intercellular communication between cytotoxic T-cells and tumor cells [172].

Along with hypoxia and acidosis tumor microenvironment is also characterized by elevated interstitial fluid pressure which in its advanced stages can cause collateral condition, accompanying cancer, namely edema. Reports on the involvement of connexins in this condition are modest. For example, it has been shown that $\mathrm{Cnx} 43$ together with aquaporin 4 are involved in the development of cerebral edema in glioma, and the expression of connexin depends on the expression of aquaporin [173]. The phenomenological data on the correlation between connexin mutations and the development of lymphoedema in breast cancer patients allow to consider connexins as prognostic markers for of predisposition to this condition which is discussed in the recent review [174].

\section{2. microRNA}

Among the types of cargo which can be transmitted through connexin-based channels, miRNAs are one of the most potent factors of TME. The transmission of miRNAs via gap junctions is reported to proceed via channels themselves or via extracellular vesicles. Thus, channels based on $\mathrm{Cnx} 43$ are reported to transmit miRNA-145 from microvascular endothelial cells to colon cancer cells leading to inhibition of angiogenesis [175]. The similar cancer inhibiting effect was recently reported in glioma where the miR-152-3p transmitted from normal astrocytes to $\mathrm{C} 6$ glioma cells via Cnx43-based channels have attenuated their migration and invasion [176]. On contrary, the miR-5096 derived from glioma cells possesses pro-invasive effect when transferred to astrocytes [177]; and hypoxia-induced miR-192-5p transferred through the Cnx43-channels from melanoma cells to cytotoxic T-lymphocytes and triggers the escape of immune surveillance [141]. In case of the exosome-mediated transmission, connexin channels are reported to recruit miRNAs to exosomes, as they possess RNA-binding motifs in their structure [108]. The miRNA transmission mediated by exosomes which contain connexins facilitates cancer progression in hypoxic conditions (Cnx46-rich exosomes) [105]. It's interesting to note that channels based on $\mathrm{Cnx} 43$ have a higher permeability for various miRNAs compared to channels formed by other connexins, such as $\mathrm{Cnx26,} \mathrm{Cnx30}$ and $\mathrm{Cnx31}$ [178], or Cnx32 and Cnx37 [179].

Summarizing these data, the trend towards tumor progression or suppression may be determined by the type of miRNA which is being transferred and the direction of transfer (from a tumor cell to a normal one or vice versa, or between tumor cells with different malignant potential). This can probably be determined by the presence, quantity, affinity and conformational availability of RNA-binding motifs in various connexins. 


\subsection{Cancer stemness}

An important factor of cancer progression is cancer stemness, which determines cancer self-renewal, dormancy and resistance to treatment [180]. Connexins are reported to participate both in inhibiting cancer stemness and facilitating it depending on the cellular and tissue context. Thus, Cnx43 SUMOylation improved gap junction functions between liver cancer stem cells which led to higher responsivity to treatment with herpes simplex virus 1 thymidine kinase (HSVtk) gene in combination with ganciclovir [181]. Ectopic expression of $\mathrm{Cnx} 43$ in lung cancer cells reduced the abundance of cancer stem cells [182]. Stemness attenuation was also reported for $\mathrm{Cnx30}$ in glioma due to its ability to interfere with the insulin-like growth factor 1 receptor [183]. On the other hand, Cnx43 was reported to mediate breast cancer immune escape by establishing communication between cancer stem cells and mesenchymal stem cells which results in preferential Treg response against T-helper 17 cells [184]. Cnx43 colocalization with $\mathrm{N}$-cadherin was characteristic to breast cancer stem cells and participated in maintaining dormancy in the bone marrow niche [185]. Cnx43-based gap junctions between lung cancer stem cells and astrocytes are reported to be necessary for brain metastasis [186]. Cnx26 was indicated to mediate self-renewal of cancer stem cells in triple-negative breast cancer by forming a signaling complex with the pluripotency transcription factor NANOG and focal adhesion kinase [60]; and drive ductal carcinoma in situ towards invasive phenotype as shown in in vitro model [187]. Similarly, hepatoma cells can acquire invasive phenotype due to the increase of cancer stem cell abundance as shown in xenograft model in vivo. It is caused by their self-renewal, mediated by high abundance of cytoplasmic Cnx32 [188]. Ectopic expression of Cnx46 in MCF-7 breast cancer cell line up-regulated the molecules associated with EMT and stemness [189]. The recent conceptual papers by J.E. Trosko discuss the hypothesis that connexins may act as key molecules which underlie cancer stem cell origin and determine the cancer stem cell type [190,191] and from broader perspective can be considered as a key in the search of the unifying origin of human diseases due to their tissue integration properties [192].

\section{Conclusions}

According to the accumulating data, connexins play a decisive regulatory role in the formation of tissue microenvironment in health and disease, in particular during the development of malignant tumors. This role is carried out both through the formation of GJIC and through the non-channel functions of the connexins. The connexins can be considered as one of the main integrating factors of tumor tissue, taking into account that gap junctions form direct bridges connecting cancer cells with each other and with stromal cells in a syncytium-like structure. Despite the fact that connexins are widely reported to be cancer suppressive, it is more correct to say that their role is multidimensional and depends on the tissue context. For example considering the functionality of connexin channels, it is important to specify whether they are localized on the plasma membrane or on the membrane of intracellular compartments (e.g. mitochondria) [90]; to which membrane domains they are attributed, namely either they are localized corresponding with the cell polarity or on the tips of cell surface protrusions (e.g. TNTs) [33]; are the channels assembled of the connexin subtype immanent for the tissue or they are comprised by the connexin of the foreign subtype [149,153].

Since connexins can be considered as the direct tissue integrators, their role in the conditioning of the morphogenic field disturbances (or overcoming these disturbances) is 
of the particular interest, especially when accepting that cancer initiation is the dynamic process which emerges by deregulating tissue constraints. The steps towards tissuerelevant research design are being made, namely a growing preference is paid to 3D in vitro models compared to conventional monolayers [193-197]. The need for such models is evidenced by the fact that the abundance of connexins in monolayers is seriously altered compared to in vivo [198]; the molecular mass of the connexins may be lower in vitro due to the lack of the posttranslational modifications which take place in vivo [199]. At the same time, the connexins abundance can be different in monolayer and in 3D in vitro models [200] or may be equal in 2D and 3D conditions but the overall cell phenotype may be drastically different due to the differences in abundance of the junction proteins [201]. To date there are no ideal models capable to recapitulate the actual tumor microenvironment. Differences in the experimental conditions result in the controversial data obtained using the existing models based on the cells of the identical origin [198,202] thus the search and investigation of new models is a relevant task .

The tight interplay of all of the participants of cell junctional complexes encourages to practice integrative approach to studying the cancer initiation and progression with assessing the participation of all junction proteins collectively, taking into account not only their presence/absence or abundance, but also the ratio of different junction proteins, their localization and functional state, etc. This might seem overly ambitious, yet the rapidly developing research methods and a plethora of elaborated tumor models along with state-of-art techniques of data analysis may one day be translated into a set of comprehensive therapeutic strategies. Here we refer to several comprehensive recent reviews [203-205] discussing the applicability of connexins as the therapeutic targets for the treatment of cancer both in terms of their suppression or recruitment.

Author Contributions: Conceptualization, I.V.B., O.M.K.; data curation, I.V.B., O.M.K., A.D.P; writing-original draft preparation, O.M.K., A.D.P.; writing-review and editing, I.V.B., O.M.K., A.D.P; visualization, O.M.K.; supervision, I.V.B.; project administration, I.V.B.; funding acquisition, I.V.B. All authors have read and agreed to the published version of the manuscript.

Funding: This research was funded by the Russian Science Foundation (project No. 1974-20168)

Acknowledgments: Authors express their deep gratitude to smart.servier.com for kindly providing the images for making the illustrations represented in this work.

Conflicts of Interest: The authors declare no conflict of interest.

\section{References}

1. Brücher, B.L.; Jamall, I.S. Somatic Mutation Theory - Why it's Wrong for Most Cancers. Cellular physiology and biochemistry : international journal of experimental cellular physiology, biochemistry, and pharmacology 2016, 38, 1663-1680, doi:10.1159/000443106.

2. Soto, A.M.; Sonnenschein, C. The tissue organization field theory of cancer: a testable replacement for the somatic mutation theory. BioEssays : news and reviews in molecular, cellular and developmental biology 2011, 33, 332-340, doi:10.1002/bies.201100025. 
3. Sonnenschein, C.; Soto, A.M. Over a century of cancer research: Inconvenient truths and promising leads. PLoS biology 2020, 18, e3000670, doi:10.1371/journal.pbio.3000670.

4. Anderson, N.M.; Simon, M.C. The tumor microenvironment. Current biology : CB 2020, 30, R921-R925, doi:10.1016/j.cub.2020.06.081.

5. Hamidi, H.; Ivaska, J. Every step of the way: integrins in cancer progression and metastasis. Nature reviews. Cancer 2018, 18, 533-548, doi:10.1038/s41568-018-0038-z.

6. Garrod, D.; Chidgey, M. Desmosome structure, composition and function. Biochimica et biophysica acta 2008, 1778, 572-587, doi:10.1016/j.bbamem.2007.07.014.

7. Takada, Y.; Ye, X.; Simon, S. The integrins. Genome biology 2007, 8, 215, doi:10.1186/gb-2007-8-5-215.

8. Harris, T.J.; Tepass, U. Adherens junctions: from molecules to morphogenesis. Nature reviews. Molecular cell biology 2010, 11, 502-514, doi:10.1038/nrm2927.

9. Tsukita, S.; Furuse, M.; Itoh, M. Multifunctional strands in tight junctions. Nature reviews. Molecular cell biology 2001, 2, 285-293, doi:10.1038/35067088.

10. Nielsen, M.S.; Axelsen, L.N.; Sorgen, P.L.; Verma, V.; Delmar, M.; HolsteinRathlou, N.H. Gap junctions. Comprehensive Physiology 2012, 2, 1981-2035, doi:10.1002/cphy.c110051.

11. Lo, C.W. Role of gap junctions in cardiac conduction and development: insights from the connexin knockout mice. Circulation research 2000, 87, 346-348, doi:10.1161/01.res.87.5.346.

12. Constantin, B.; Cronier, L. Involvement of gap junctional communication in myogenesis. International review of cytology 2000, 196, 1-65, doi:10.1016/s00747696(00)96001-7.

13. Pogoda, K.; Kameritsch, P. Molecular regulation of myoendothelial gap junctions. Current opinion in pharmacology 2019, 45, 16-22, doi:10.1016/j.coph.2019.03.006.

14. El-Sabban, M.E.; Abi-Mosleh, L.F.; Talhouk, R.S. Developmental Regulation of Gap Junctions and Their Role in Mammary Epithelial Cell Differentiation. Journal of Mammary Gland Biology and Neoplasia 2003, 8, 463-473, doi:10.1023/B:JOMG.0000017432.04930.76.

15. Berthoud, V.M.; Minogue, P.J.; Osmolak, P.; Snabb, J.I.; Beyer, E.C. Roles and regulation of lens epithelial cell connexins. FEBS letters 2014, 588, 1297-1303, doi:10.1016/j.febslet.2013.12.024.

16. Bosco, D.; Haefliger, J.A.; Meda, P. Connexins: key mediators of endocrine function. Physiological reviews 2011, 91, 1393-1445, doi:10.1152/physrev.00027.2010.

17. Vinken, M.; Decrock, E.; Leybaert, L.; Bultynck, G.; Himpens, B.; Vanhaecke, T.; Rogiers, V. Non-channel functions of connexins in cell growth and cell death. Biochimica et biophysica acta 2012, 1818, 2002-2008, doi:10.1016/j.bbamem.2011.06.011.

18. Van Campenhout, R.; Cooreman, A.; Leroy, K.; Rusiecka, O.M.; Van Brantegem, P.; Annaert, P.; Muyldermans, S.; Devoogdt, N.; Cogliati, B.; Kwak, B.R.; et al. Non- 
canonical roles of connexins. Progress in biophysics and molecular biology 2020, 153, 35-41, doi:10.1016/j.pbiomolbio.2020.03.002.

19. Aasen, T.; Mesnil, M.; Naus, C.C.; Lampe, P.D.; Laird, D.W. Gap junctions and cancer: communicating for 50 years. Nature reviews. Cancer 2016, 16, 775-788, doi:10.1038/nrc.2016.105.

20. Mulkearns-Hubert, E.E.; Reizes, O.; Lathia, J.D. Connexins in Cancer: Jekyll or Hyde? Biomolecules 2020, 10, doi:10.3390/biom10121654.

21. Abascal, F.; Zardoya, R. Evolutionary analyses of gap junction protein families. Biochimica et biophysica acta 2013, 1828, 4-14, doi:10.1016/j.bbamem.2012.02.007.

22. Skerrett, I.M.; Williams, J.B. A structural and functional comparison of gap junction channels composed of connexins and innexins. Developmental neurobiology 2017, 77, 522-547, doi:10.1002/dneu.22447.

23. Chothia, C.; Gough, J.; Vogel, C.; Teichmann, S.A. Evolution of the protein repertoire. Science (New York, N.Y.) 2003, 300, 1701-1703, doi:10.1126/science.1085371.

24. Mikalsen, S.O.; S, Í.K.; Tausen, M. Connexins during 500 Million Years-From Cyclostomes to Mammals. International journal of molecular sciences 2021, 22, doi:10.3390/ijms22041584.

25. Beyer, E.; Berthoud, V. The Family of Connexin Genes. 2009; pp. 3-26.

26. Willecke, K.; Eiberger, J.; Degen, J.; Eckardt, D.; Romualdi, A.; Güldenagel, M.; Deutsch, U.; Söhl, G. Structural and functional diversity of connexin genes in the mouse and human genome. Biological chemistry 2002, 383, 725-737, doi:10.1515/bc.2002.076.

27. Oyamada, M.; Takebe, K.; Oyamada, Y. Regulation of connexin expression by transcription factors and epigenetic mechanisms. Biochimica et biophysica acta 2013, 1828, 118-133, doi:10.1016/j.bbamem.2011.12.031.

28. J, J.; Vanisree, A.J.; Ravisankar, S.; K, R. Site specific hypermethylation of CpGs in Connexin genes 30, 26 and 43 in different grades of glioma and attenuated levels of their mRNAs. The International journal of neuroscience 2019, 129, 273-282, doi:10.1080/00207454.2018.1526802.

29. Sirnes, S.; Honne, H.; Ahmed, D.; Danielsen, S.A.; Rognum, T.O.; Meling, G.I.; Leithe, E.; Rivedal, E.; Lothe, R.A.; Lind, G.E. DNA methylation analyses of the connexin gene family reveal silencing of GJC1 (Connexin45) by promoter hypermethylation in colorectal cancer. Epigenetics 2011, 6, 602-609, doi:10.4161/epi.6.5.15237.

30. Xiao, S.; Shimura, D.; Baum, R.; Hernandez, D.M.; Agvanian, S.; Nagaoka, Y.; Katsumata, M.; Lampe, P.D.; Kleber, A.G.; Hong, T.; et al. Auxiliary trafficking subunit GJA1-20k protects connexin-43 from degradation and limits ventricular arrhythmias. The Journal of clinical investigation 2020, 130, 4858-4870, doi:10.1172/jci134682.

31. Basheer, W.A.; Xiao, S.; Epifantseva, I.; Fu, Y.; Kleber, A.G.; Hong, T.; Shaw, R.M. GJA1-20k Arranges Actin to Guide Cx43 Delivery to Cardiac Intercalated Discs. Circulation research 2017, 121, 1069-1080, doi:10.1161/circresaha.117.311955. 
32. Fu, Y.; Zhang, S.S.; Xiao, S.; Basheer, W.A.; Baum, R.; Epifantseva, I.; Hong, T.; Shaw, R.M. Cx43 Isoform GJA1-20k Promotes Microtubule Dependent Mitochondrial Transport. Frontiers in physiology 2017, 8, 905, doi:10.3389/fphys.2017.00905.

33. Tishchenko, A.; Azorín, D.D.; Vidal-Brime, L.; Muñoz, M.J.; Arenas, P.J.; Pearce, C.; Girao, H.; Ramón, Y.C.S.; Aasen, T. Cx43 and Associated Cell Signaling Pathways Regulate Tunneling Nanotubes in Breast Cancer Cells. Cancers 2020, 12, doi:10.3390/cancers12102798.

34. Aasen, T.; Johnstone, S.; Vidal-Brime, L.; Lynn, K.S.; Koval, M. Connexins: Synthesis, Post-Translational Modifications, and Trafficking in Health and Disease. International journal of molecular sciences 2018, 19, doi:10.3390/ijms19051296.

35. Bai, D.; Yue, B.; Aoyama, H. Crucial motifs and residues in the extracellular loops influence the formation and specificity of connexin docking. Biochimica et biophysica acta. Biomembranes 2018, 1860, 9-21, doi:10.1016/j.bbamem.2017.07.003.

36. Retamal, M.A.; García, I.E.; Pinto, B.I.; Pupo, A.; Báez, D.; Stehberg, J.; Del Rio, R.; González, C. Extracellular Cysteine in Connexins: Role as Redox Sensors. Frontiers in physiology 2016, 7, 1, doi:10.3389/fphys.2016.00001.

37. Zhang, K.; Guan, Q.W.; Zhou, X.Y.; Xia, Q.X.; Yin, X.X.; Zhou, H.H.; Mao, X.Y. The mutual interplay of redox signaling and connexins. Journal of molecular medicine (Berlin, Germany) 2021, 99, 933-941, doi:10.1007/s00109-021-02084-0.

38. Olbina, G.; Eckhart, W. Mutations in the second extracellular region of connexin 43 prevent localization to the plasma membrane, but do not affect its ability to suppress cell growth. Molecular cancer research : MCR 2003, 1, 690-700.

39. Kyle, J.W.; Minogue, P.J.; Thomas, B.C.; Domowicz, D.A.; Berthoud, V.M.; Hanck, D.A.; Beyer, E.C. An intact connexin N-terminus is required for function but not gap junction formation. Journal of cell science 2008, 121, 2744-2750, doi:10.1242/jcs.032482.

40. Leithe, E.; Mesnil, M.; Aasen, T. The connexin 43 C-terminus: A tail of many tales. Biochimica et biophysica acta. Biomembranes 2018, 1860, 48-64, doi:10.1016/j.bbamem.2017.05.008.

41. Giepmans, B.N.; Hengeveld, T.; Postma, F.R.; Moolenaar, W.H. Interaction of CSrc with gap junction protein connexin-43. Role in the regulation of cell-cell communication. The Journal of biological chemistry 2001, 276, 8544-8549, doi:10.1074/jbc.M005847200.

42. Giepmans, B.N.; Verlaan, I.; Moolenaar, W.H. Connexin-43 interactions with ZO-1 and alpha- and beta-tubulin. Cell communication \& adhesion 2001, 8, 219-223, doi:10.3109/15419060109080727.

43. Jin, C.; Martyn, K.D.; Kurata, W.E.; Warn-Cramer, B.J.; Lau, A.F. Connexin43 PDZ2 binding domain mutants create functional gap junctions and exhibit altered phosphorylation. Cell communication \& adhesion 2004, 11, 67-87, doi:10.1080/15419060490951781.

44. Jacobsen, N.L.; Pontifex, T.K.; Li, H.; Solan, J.L.; Lampe, P.D.; Sorgen, P.L.; Burt, J.M. Regulation of $\mathrm{C} \times 37$ channel and growth-suppressive properties by phosphorylation. Journal of cell science 2017, 130, 3308-3321, doi:10.1242/jcs.202572. 
45. Kuang, J.-Y.; Guo, Y.-F.; Chen, Y.; Wang, J.; Duan, J.-J.; He, X.-L.; Li, L.; Yu, S.C.; Bian, X.-W. Connexin 43 C-terminus directly inhibits the hyperphosphorylation of Akt/ERK through protein-protein interactions in glioblastoma. Cancer science 2018, 109, 2611-2622, doi:10.1111/cas.13707.

46. Talaverón, R.; Matarredona, E.R.; Herrera, A.; Medina, J.M.; Tabernero, A. Connexin43 Region 266-283, via Src Inhibition, Reduces Neural Progenitor Cell Proliferation Promoted by EGF and FGF-2 and Increases Astrocytic Differentiation. International journal of molecular sciences 2020, 21, doi:10.3390/ijms21228852.

47. Brandao, M.; Simon, T.; Critchley, G.; Giamas, G. Astrocytes, the rising stars of the glioblastoma microenvironment. Glia 2019, 67, 779-790, doi:10.1002/glia.23520.

48. Sin, W.C.; Aftab, Q.; Bechberger, J.F.; Leung, J.H.; Chen, H.; Naus, C.C. Astrocytes promote glioma invasion via the gap junction protein connexin43. Oncogene 2016, 35, 1504-1516, doi:10.1038/onc.2015.210.

49. McCutcheon, S.; Spray, D.C. Abstract 2885: Connexin 43-dependent miRNA transfer drives perivascular glioma invasion through dysregulation of astrocytes. Cancer research 2021, 81, 2885-2885, doi:10.1158/1538-7445.am2021-2885.

50. Morel, S.; Burnier, L.; Roatti, A.; Chassot, A.; Roth, I.; Sutter, E.; Galan, K.; Pfenniger, A.; Chanson, M.; Kwak, B.R. Unexpected role for the human Cx37 C1019T polymorphism in tumour cell proliferation. Carcinogenesis 2010, 31, 1922-1931, doi:10.1093/carcin/bgq170.

51. Tetenborg, S.; Wang, H.Y.; Nemitz, L.; Depping, A.; Espejo, A.B.; Aseervatham, J.; Bedford, M.T.; Janssen-Bienhold, U.; O'Brien, J.; Dedek, K. Phosphorylation of Connexin36 near the C-terminus switches binding affinities for PDZ-domain and 14-3-3 proteins in vitro. Scientific reports 2020, 10, 18378-18378, doi:10.1038/s41598-02075375-0.

52. Khorrami, A.; Sharif Bagheri, M.; Tavallaei, M.; Gharechahi, J. The functional significance of 14-3-3 proteins in cancer: focus on lung cancer. Hormone molecular biology and clinical investigation 2017, 32, doi:10.1515/hmbci-2017-0032.

53. Zhao, S.; Li, B.; Li, C.; Gao, H.; Miao, Y.; He, Y.; Wang, H.; Gong, L.; Li, D.; Zhang, Y.; et al. The Apoptosis Regulator 14-3-3n and Its Potential as a Therapeutic Target in Pituitary Oncocytoma. Frontiers in endocrinology 2019, 10, 797, doi:10.3389/fendo.2019.00797.

54. Talhouk, R.S.; Fares, M.B.; Rahme, G.J.; Hariri, H.H.; Rayess, T.; Dbouk, H.A.; Bazzoun, D.; Al-Labban, D.; El-Sabban, M.E. Context dependent reversion of tumor phenotype by connexin-43 expression in MDA-MB231 cells and MCF-7 cells: role of $\beta$ catenin/connexin43 association. Experimental cell research 2013, 319, 3065-3080, doi:10.1016/j.yexcr.2013.10.002.

55. Good, M.E.; Ek-Vitorín, J.F.; Burt, J.M. Structural determinants and proliferative consequences of connexin 37 hemichannel function in insulinoma cells. The Journal of biological chemistry 2014, 289, 30379-30386, doi:10.1074/jbc.M114.583054.

56. Sun, P.; Dong, L.; MacDonald, A.I.; Akbari, S.; Edward, M.; Hodgins, M.B.; Johnstone, S.R.; Graham, S.V. HPV16 E6 Controls the Gap Junction Protein Cx43 in Cervical Tumour Cells. Viruses 2015, 7, 5243-5256, doi:10.3390/v7102871. 
57. likawa, N.; Yamamoto, Y.; Kawasaki, Y.; Nishijima-Matsunobu, A.; Suzuki, M.; Yamada, T.; Omori, Y. Intrinsic Oncogenic Function of Intracellular Connexin26 Protein in Head and Neck Squamous Cell Carcinoma Cells. International journal of molecular sciences 2018, 19, 2134, doi:10.3390/ijms19072134.

58. Xiao, D.; Chen, S.; Shao, Q.; Chen, J.; Bijian, K.; Laird, D.W.; Alaoui-Jamali, M.A. Dynamin 2 interacts with connexin 26 to regulate its degradation and function in gap junction formation. The international journal of biochemistry \& cell biology $2014,55,288$ 297, doi:10.1016/j.biocel.2014.09.021.

59. Trochet, D.; Bitoun, M. A review of Dynamin 2 involvement in cancers highlights a promising therapeutic target. Journal of experimental \& clinical cancer research : CR 2021, 40, 238, doi:10.1186/s13046-021-02045-y.

60. Thiagarajan, P.S.; Sinyuk, M.; Turaga, S.M.; Mulkearns-Hubert, E.E.; Hale, J.S.; Rao, V.; Demelash, A.; Saygin, C.; China, A.; Alban, T.J.; et al. Cx26 drives self-renewal in triple-negative breast cancer via interaction with NANOG and focal adhesion kinase. Nature Communications 2018, 9, 578, doi:10.1038/s41467-018-02938-1.

61. Weber, P.A.; Chang, H.C.; Spaeth, K.E.; Nitsche, J.M.; Nicholson, B.J. The permeability of gap junction channels to probes of different size is dependent on connexin composition and permeant-pore affinities. Biophysical journal 2004, 87, 958-973, doi:10.1529/biophysj.103.036350.

62. Fleishman, S.J.; Unger, V.M.; Yeager, M.; Ben-Tal, N. A Calpha model for the transmembrane alpha helices of gap junction intercellular channels. Molecular cell 2004, 15, 879-888, doi:10.1016/j.molcel.2004.08.016.

63. Zhou, X.W.; Pfahnl, A.; Werner, R.; Hudder, A.; Llanes, A.; Luebke, A.; Dahl, G. Identification of a pore lining segment in gap junction hemichannels. Biophysical journal 1997, 72, 1946-1953, doi:10.1016/s0006-3495(97)78840-4.

64. Kronengold, J.; Srinivas, M.; Verselis, V.K. The N-terminal half of the connexin protein contains the core elements of the pore and voltage gates. The Journal of membrane biology 2012, 245, 453-463, doi:10.1007/s00232-012-9457-z.

65. Flores, J.A.; Haddad, B.G.; Dolan, K.A.; Myers, J.B.; Yoshioka, C.C.; Copperman, J.; Zuckerman, D.M.; Reichow, S.L. Connexin-46/50 in a dynamic lipid environment resolved by CryoEM at $1.9 \AA$. Nat Commun 2020, 11, 4331, doi:10.1038/s41467-02018120-5.

66. Khan, A.K.; Jagielnicki, M.; Mclntire, W.E.; Purdy, M.D.; Dharmarajan, V.; Griffin, P.R.; Yeager, M. A Steric "Ball-and-Chain" Mechanism for pH-Mediated Regulation of Gap Junction Channels. Cell reports 2020, 31, 107482, doi:10.1016/j.celrep.2020.03.046.

67. Lee, H.J.; Jeong, H.; Hyun, J.; Ryu, B.; Park, K.; Lim, H.H.; Yoo, J.; Woo, J.S. Cryo-EM structure of human Cx31.3/GJC3 connexin hemichannel. Science advances 2020, 6, eaba4996, doi:10.1126/sciadv.aba4996.

68. Khan, A.K.; Jagielnicki, M.; Bennett, B.C.; Purdy, M.D.; Yeager, M. Cryo-EM structure of an open conformation of a gap junction hemichannel in lipid bilayer nanodiscs. Structure (London, England : 1993) 2021, 29, 1040-1047.e1043, doi:10.1016/j.str.2021.05.010. 
69. Lagree, V.; Brunschwig, K.; Lopez, P.; Gilula, N.B.; Richard, G.; Falk, M.M. Specific amino-acid residues in the $\mathrm{N}$-terminus and TM3 implicated in channel function and oligomerization compatibility of connexin43. Journal of cell science 2003, 116, 31893201, doi:10.1242/jcs.00604.

70. Smith, T.D.; Mohankumar, A.; Minogue, P.J.; Beyer, E.C.; Berthoud, V.M.; Koval, $M$. Cytoplasmic amino acids within the membrane interface region influence connexin oligomerization. The Journal of membrane biology 2012, 245, 221-230, doi:10.1007/s00232-012-9443-5.

71. Koval, M.; Molina, S.A.; Burt, J.M. Mix and match: investigating heteromeric and heterotypic gap junction channels in model systems and native tissues. FEBS letters 2014, 588, 1193-1204, doi:10.1016/j.febslet.2014.02.025.

72. Cascio, M. Connexins and their environment: effects of lipids composition on ion channels. Biochimica et biophysica acta 2005, 1711, 142-153, doi:10.1016/j.bbamem.2004.12.001.

73. McCutcheon, S.; Stout, R.F., Jr.; Spray, D.C. The dynamic Nexus: gap junctions control protein localization and mobility in distinct and surprising ways. Sci Rep 2020, 10, 17011, doi:10.1038/s41598-020-73892-6.

74. Govindarajan, R.; Chakraborty, S.; Johnson, K.E.; Falk, M.M.; Wheelock, M.J.; Johnson, K.R.; Mehta, P.P. Assembly of connexin43 into gap junctions is regulated differentially by $\mathrm{E}$-cadherin and $\mathrm{N}$-cadherin in rat liver epithelial cells. Molecular biology of the cell 2010, 21, 4089-4107, doi:10.1091/mbc.E10-05-0403.

75. Chakraborty, S.; Mitra, S.; Falk, M.M.; Caplan, S.H.; Wheelock, M.J.; Johnson, K.R.; Mehta, P.P. E-cadherin differentially regulates the assembly of Connexin43 and Connexin32 into gap junctions in human squamous carcinoma cells. The Journal of biological chemistry 2010, 285, 10761-10776, doi:10.1074/jbc.M109.053348.

76. Guerrier, A.; Fonlupt, P.; Morand, I.; Rabilloud, R.; Audebet, C.; Krutovskikh, V.; Gros, D.; Rousset, B.; Munari-Silem, Y. Gap junctions and cell polarity: connexin32 and connexin43 expressed in polarized thyroid epithelial cells assemble into separate gap junctions, which are located in distinct regions of the lateral plasma membrane domain. Journal of cell science 1995, 108 ( Pt 7), 2609-2617.

77. Bazzoun, D.; Adissu, H.A.; Wang, L.; Urazaev, A.; Tenvooren, I.; Fostok, S.F.; Chittiboyina, S.; Sturgis, J.; Hodges, K.; Chandramouly, G.; et al. Connexin 43 maintains tissue polarity and regulates mitotic spindle orientation in the breast epithelium. Journal of cell science 2019, 132, doi:10.1242/jcs.223313.

78. Stoessel, A.; Himmerkus, N.; Bleich, M.; Bachmann, S.; Theilig, F. Connexin 37 is localized in renal epithelia and responds to changes in dietary salt intake. American journal of physiology. Renal physiology 2010, 298, F216-223, doi:10.1152/ajprenal.00295.2009.

79. Francis, R.; Xu, X.; Park, H.; Wei, C.J.; Chang, S.; Chatterjee, B.; Lo, C. Connexin43 modulates cell polarity and directional cell migration by regulating microtubule dynamics. PloS one 2011, 6, e26379, doi:10.1371/journal.pone.0026379. 
80. Takeuchi, Y.; Narumi, R.; Akiyama, R.; Vitiello, E.; Shirai, T.; Tanimura, N.; Kuromiya, K.; Ishikawa, S.; Kajita, M.; Tada, M.; et al. Calcium Wave Promotes Cell Extrusion. Current biology : CB 2020, 30, 670-681.e676, doi:10.1016/j.cub.2019.11.089.

81. Caillou, B.; Talbot, M.; Weyemi, U.; Pioche-Durieu, C.; Al Ghuzlan, A.; Bidart, J.M.; Chouaib, S.; Schlumberger, M.; Dupuy, C. Tumor-associated macrophages (TAMs) form an interconnected cellular supportive network in anaplastic thyroid carcinoma. PloS one 2011, 6, e22567, doi:10.1371/journal.pone.0022567.

82. Okafo, G.; Prevedel, L.; Eugenin, E. Tunneling nanotubes (TNT) mediate longrange gap junctional communication: Implications for HIV cell to cell spread. Sci Rep 2017, 7, 16660, doi:10.1038/s41598-017-16600-1.

83. Wang, X.; Veruki, M.L.; Bukoreshtliev, N.V.; Hartveit, E.; Gerdes, H.H. Animal cells connected by nanotubes can be electrically coupled through interposed gap-junction channels. Proceedings of the National Academy of Sciences of the United States of America 2010, 107, 17194-17199, doi:10.1073/pnas.1006785107.

84. Behrens, J.; Kameritsch, P.; Wallner, S.; Pohl, U.; Pogoda, K. The carboxyl tail of Cx43 augments p38 mediated cell migration in a gap junction-independent manner. European journal of cell biology 2010, 89, 828-838, doi:10.1016/j.ejcb.2010.06.003.

85. Kameritsch, P.; Kiemer, F.; Beck, H.; Pohl, U.; Pogoda, K. Cx43 increases serum induced filopodia formation via activation of p21-activated protein kinase 1. Biochimica et biophysica acta 2015, 1853, 2907-2917, doi:10.1016/j.bbamcr.2015.08.004.

86. Pulze, L.; Congiu, T.; Brevini, T.A.L.; Grimaldi, A.; Tettamanti, G.; D'Antona, P.; Baranzini, N.; Acquati, F.; Ferraro, F.; de Eguileor, M. MCF7 Spheroid Development: New Insight about Spatio/Temporal Arrangements of TNTs, Amyloid Fibrils, Cell Connections, and Cellular Bridges. International journal of molecular sciences 2020, 21, doi:10.3390/ijms21155400.

87. Kozoriz, M.G.; Church, J.; Ozog, M.A.; Naus, C.C.; Krebs, C. Temporary sequestration of potassium by mitochondria in astrocytes. The Journal of biological chemistry 2010, 285, 31107-31119, doi:10.1074/jbc.M109.082073.

88. Wang, M.; Smith, K.; Yu, Q.; Miller, C.; Singh, K.; Sen, C.K. Mitochondrial connexin 43 in sex-dependent myocardial responses and estrogen-mediated cardiac protection following acute ischemia/reperfusion injury. Basic research in cardiology 2019, 115, 1, doi:10.1007/s00395-019-0759-5.

89. Boengler, K.; Stahlhofen, S.; van de Sand, A.; Gres, P.; Ruiz-Meana, M.; GarciaDorado, D.; Heusch, G.; Schulz, R. Presence of connexin 43 in subsarcolemmal, but not in interfibrillar cardiomyocyte mitochondria. Basic research in cardiology 2009, 104, 141 147, doi:10.1007/s00395-009-0007-5.

90. Martins-Marques, T.; Ribeiro-Rodrigues, T.; Batista-Almeida, D.; Aasen, T.; Kwak, B.R.; Girao, H. Biological Functions of Connexin43 Beyond Intercellular Communication. Trends in cell biology 2019, 29, 835-847, doi:10.1016/j.tcb.2019.07.001.

91. Artesi, M.; Kroonen, J.; Bredel, M.; Nguyen-Khac, M.; Deprez, M.; Schoysman, L.; Poulet, C.; Chakravarti, A.; Kim, H.; Scholtens, D.; et al. Connexin 30 expression inhibits growth of human malignant gliomas but protects them against radiation therapy. Neurooncology 2015, 17, 392-406, doi:10.1093/neuonc/nou215. 
92. Halestrap, A.P. Mitochondria and Preconditioning. Circulation research 2006, 99, 10-12, doi:doi:10.1161/01.RES.0000233145.94073.b8.

93. Kim, I.S.; Ganesan, P.; Choi, D.K. Cx43 Mediates Resistance against MPP+ Induced Apoptosis in SH-SY5Y Neuroblastoma Cells via Modulating the Mitochondrial Apoptosis Pathway. International journal of molecular sciences 2016, 17, doi:10.3390/ijms17111819.

94. Lu, G.; Haider, H.; Porollo, A.; Ashraf, M. Mitochondria-specific transgenic overexpression of connexin-43 simulates preconditioning-induced cytoprotection of stem cells. Cardiovascular research 2010, 88, 277-286, doi:10.1093/cvr/cvq293.

95. Boengler, K.; Ruiz-Meana, M.; Gent, S.; Ungefug, E.; Soetkamp, D.; Miro-Casas, E.; Cabestrero, A.; Fernandez-Sanz, C.; Semenzato, M.; Di Lisa, F.; et al. Mitochondrial connexin 43 impacts on respiratory complex I activity and mitochondrial oxygen consumption. Journal of cellular and molecular medicine 2012, 16, 1649-1655, doi:10.1111/j.1582-4934.2011.01516.x.

96. Uzu, M.; Sato, H.; Shimizu, A.; Shibata, Y.; Ueno, K.; Hisaka, A. Connexin 43 enhances Bax activation via JNK activation in sunitinib-induced apoptosis in mesothelioma cells. Journal of pharmacological sciences 2017, 134, 101-107, doi:10.1016/j.jphs.2017.05.005.

97. Zeng, Q.L.; Chiang, H.; Hu, G.L.; Mao, G.G.; Fu, Y.T.; Lu, D.Q. ELF magnetic fields induce internalization of gap junction protein connexin 43 in Chinese hamster lung cells. Bioelectromagnetics 2003, 24, 134-138, doi:10.1002/bem.10070.

98. Lohmann, C.H.; Schwartz, Z.; Liu, Y.; Li, Z.; Simon, B.J.; Sylvia, V.L.; Dean, D.D.; Bonewald, L.F.; Donahue, H.J.; Boyan, B.D. Pulsed electromagnetic fields affect phenotype and connexin 43 protein expression in MLO-Y4 osteocyte-like cells and ROS 17/2.8 osteoblast-like cells. Journal of orthopaedic research : official publication of the Orthopaedic Research Society 2003, 21, 326-334, doi:10.1016/s0736-0266(02)00137-7.

99. Yamaguchi, D.T.; Huang, J.; Ma, D.; Wang, P.K. Inhibition of gap junction intercellular communication by extremely low-frequency electromagnetic fields in osteoblast-like models is dependent on cell differentiation. Journal of cellular physiology 2002, 190, 180-188, doi:10.1002/jcp.10047.

100. Morabito, C.; Steimberg, N.; Rovetta, F.; Boniotti, J.; Guarnieri, S.; Mazzoleni, G.; Mariggiò, M.A. Extremely Low-Frequency Electromagnetic Fields Affect Myogenic Processes in C2C12 Myoblasts: Role of Gap-Junction-Mediated Intercellular Communication. BioMed research international 2017, 2017, 2460215, doi:10.1155/2017/2460215.

101. Zeng, S.G.; Lin, X.; Liu, J.C.; Zhou, J. Hypoxia-induced internalization of connexin 26 and connexin 43 in pulmonary epithelial cells is involved in the occurrence of non-small cell lung cancer via the P53/MDM2 signaling pathway. International journal of oncology 2019, 55, 845-859, doi:10.3892/ijo.2019.4867.

102. Kotini, M.; Barriga, E.H.; Leslie, J.; Gentzel, M.; Rauschenberger, V.; Schambony, A.; Mayor, R. Gap junction protein Connexin-43 is a direct transcriptional regulator of Ncadherin in vivo. Nat Commun 2018, 9, 3846, doi:10.1038/s41467-018-06368-x. 
103. Wortzel, I.; Dror, S.; Kenific, C.M.; Lyden, D. Exosome-Mediated Metastasis: Communication from a Distance. Developmental cell 2019, 49, 347-360, doi:10.1016/j.devcel.2019.04.011.

104. Dai, J.; Su, Y.; Zhong, S.; Cong, L.; Liu, B.; Yang, J.; Tao, Y.; He, Z.; Chen, C.; Jiang, Y. Exosomes: key players in cancer and potential therapeutic strategy. Signal transduction and targeted therapy 2020, 5, 145, doi:10.1038/s41392-020-00261-0.

105. Acuña, R.A.; Varas-Godoy, M.; Berthoud, V.M.; Alfaro, I.E.; Retamal, M.A. Connexin-46 Contained in Extracellular Vesicles Enhance Malignancy Features in Breast Cancer Cells. Biomolecules 2020, 10, doi:10.3390/biom10050676.

106. Soares, A.R.; Martins-Marques, T.; Ribeiro-Rodrigues, T.; Ferreira, J.V.; Catarino, S.; Pinho, M.J.; Zuzarte, M.; Isabel Anjo, S.; Manadas, B.; J, P.G.S.; et al. Gap junctional protein $\mathrm{Cx} 43$ is involved in the communication between extracellular vesicles and mammalian cells. Sci Rep 2015, 5, 13243, doi:10.1038/srep13243.

107. Yang, Z.J.; Zhang, L.L.; Bi, Q.C.; Gan, L.J.; Wei, M.J.; Hong, T.; Tan, R.J.; Lan, X.M.; Liu, L.H.; Han, X.J.; et al. Exosomal connexin 43 regulates the resistance of glioma cells to temozolomide. Oncology reports 2021, 45, doi:10.3892/or.2021.7995.

108. Varela-Eirin, M.; Varela-Vazquez, A.; Rodríguez-Candela Mateos, M.; VilaSanjurjo, A.; Fonseca, E.; Mascareñas, J.L.; Eugenio Vázquez, M.; Mayan, M.D. Recruitment of RNA molecules by connexin RNA-binding motifs: Implication in RNA and DNA transport through microvesicles and exosomes. Biochimica et biophysica acta. Molecular cell research 2017, 1864, 728-736, doi:10.1016/j.bbamcr.2017.02.001.

109. Decrock, E.; Vinken, M.; De Vuyst, E.; Krysko, D.V.; D'Herde, K.; Vanhaecke, T.; Vandenabeele, P.; Rogiers, V.; Leybaert, L. Connexin-related signaling in cell death: to live or let die? Cell death and differentiation 2009, 16, 524-536, doi:10.1038/cdd.2008.196.

110. Khalil, A.A.; llina, O.; Vasaturo, A.; Venhuizen, J.H.; Vullings, M.; Venhuizen, V.; Bilos, A.; Figdor, C.G.; Span, P.N.; Friedl, P. Collective invasion induced by an autocrine purinergic loop through connexin-43 hemichannels. The Journal of cell biology 2020, 219, doi:10.1083/jcb.201911120.

111. Turovsky, E.A.; Varlamova, E.G. Mechanism of $\mathrm{Ca}(2+)$-Dependent Pro-Apoptotic Action of Selenium Nanoparticles, Mediated by Activation of Cx43 Hemichannels. Biology 2021, 10, doi:10.3390/biology 10080743.

112. Nardin, C.; Peres, C.; Putti, S.; Orsini, T.; Colussi, C.; Mazzarda, F.; Raspa, M.; Scavizzi, F.; Salvatore, A.M.; Chiani, F.; et al. Connexin Hemichannel Activation by SNitrosoglutathione Synergizes Strongly with Photodynamic Therapy Potentiating AntiTumor Bystander Killing. Cancers 2021, 13, doi:10.3390/cancers 13205062.

113. Zhou, J.Z.; Riquelme, M.A.; Gu, S.; Kar, R.; Gao, X.; Sun, L.; Jiang, J.X. Osteocytic connexin hemichannels suppress breast cancer growth and bone metastasis. Oncogene 2016, 35, 5597-5607, doi:10.1038/onc.2016.101.

114. Carmeliet, E. Conduction in cardiac tissue. Historical reflections. Physiological Reports 2019, 7, e13860, doi:https://doi.org/10.14814/phy2.13860. 
115. McEvoy, E.; Han, Y.L.; Guo, M.; Shenoy, V.B. Gap junctions amplify spatial variations in cell volume in proliferating tumor spheroids. Nature Communications 2020, 11, 6148, doi:10.1038/s41467-020-19904-5.

116. Zoellner, H.; Paknejad, N.; Cornwell, J.A.; Chami, B.; Romin, Y.; Boyko, V.; Fujisawa, S.; Kelly, E.; Lynch, G.W.; Rogers, G.; et al. Potential Hydrodynamic Cytoplasmic Transfer between Mammalian Cells: Cell-Projection Pumping. Biophysical journal 2020, 118, 1248-1260, doi:10.1016/j.bpj.2020.01.025.

117. Boucher, J.; Balandre, A.C.; Debant, M.; Vix, J.; Harnois, T.; Bourmeyster, N.; Péraudeau, E.; Chépied, A.; Clarhaut, J.; Debiais, F.; et al. Cx43 Present at the Leading Edge Membrane Governs Promigratory Effects of Osteoblast-Conditioned Medium on Human Prostate Cancer Cells in the Context of Bone Metastasis. Cancers 2020, 12, doi:10.3390/cancers12103013.

118. Wang, H.; Tian, L.; Liu, J.; Goldstein, A.; Bado, I.; Zhang, W.; Arenkiel, B.R.; Li, Z.; Yang, M.; Du, S.; et al. The Osteogenic Niche Is a Calcium Reservoir of Bone Micrometastases and Confers Unexpected Therapeutic Vulnerability. Cancer cell 2018, 34, 823-839.e827, doi:10.1016/j.ccell.2018.10.002.

119. Waning, D.L.; Guise, T.A.; Mohammad, K.S. A "Connexin" Responsible for the Fatal Attraction of Cancer to Bone. Cell metabolism 2019, 29, 6-8, doi:10.1016/j.cmet.2018.12.014.

120. Weiler, J.; Dittmar, T. Cell Fusion in Human Cancer: The Dark Matter Hypothesis. Cells 2019, 8, doi:10.3390/cells8020132.

121. Hass, R.; von der Ohe, J.; Dittmar, T. Cancer Cell Fusion and Post-Hybrid Selection Process (PHSP). Cancers 2021, 13, doi:10.3390/cancers13184636.

122. Wang, H.F.; Xiang, W.; Xue, B.Z.; Wang, Y.H.; Yi, D.Y.; Jiang, X.B.; Zhao, H.Y.; $\mathrm{Fu}, \mathrm{P}$. Cell fusion in cancer hallmarks: Current research status and future indications. Oncology letters 2021, 22, 530, doi:10.3892/ol.2021.12791.

123. Laberge, G.S.; Duvall, E.; Haedicke, K.; Pawelek, J. Leukocyte-Cancer Cell Fusion-Genesis of a Deadly Journey. Cells 2019, 8, doi:10.3390/cells8020170.

124. Delespaul, L.; Merle, C.; Lesluyes, T.; Lagarde, P.; Le Guellec, S.; Pérot, G.; Baud, J.; Carlotti, M.; Danet, C.; Fèvre, M.; et al. Fusion-mediated chromosomal instability promotes aneuploidy patterns that resemble human tumors. Oncogene 2019, 38, 60836094, doi:10.1038/s41388-019-0859-6.

125. Delespaul, L.; Gélabert, C.; Lesluyes, T.; Le Guellec, S.; Pérot, G.; Leroy, L.; Baud, J.; Merle, C.; Lartigue, L.; Chibon, F. Cell-cell fusion of mesenchymal cells with distinct differentiations triggers genomic and transcriptomic remodelling toward tumour aggressiveness. Sci Rep 2020, 10, 21634, doi:10.1038/s41598-020-78502-z.

126. Frendo, J.L.; Cronier, L.; Bertin, G.; Guibourdenche, J.; Vidaud, M.; Evain-Brion, D.; Malassine, A. Involvement of connexin 43 in human trophoblast cell fusion and differentiation. Journal of cell science 2003, 116, 3413-3421, doi:10.1242/jcs.00648.

127. Frendo, J.L.; Olivier, D.; Cheynet, V.; Blond, J.L.; Bouton, O.; Vidaud, M.; Rabreau, M.; Evain-Brion, D.; Mallet, F. Direct involvement of HERV-W Env glycoprotein in human 
trophoblast cell fusion and differentiation. Molecular and cellular biology 2003, 23, 35663574, doi:10.1128/mcb.23.10.3566-3574.2003.

128. Dunk, C.E.; Gellhaus, A.; Drewlo, S.; Baczyk, D.; Pötgens, A.J.; Winterhager, E.; Kingdom, J.C.; Lye, S.J. The molecular role of connexin 43 in human trophoblast cell fusion. Biology of reproduction 2012, 86, 115, doi:10.1095/biolreprod.111.096925.

129. Dupressoir, A.; Vernochet, C.; Harper, F.; Guégan, J.; Dessen, P.; Pierron, G.; Heidmann, T. A pair of co-opted retroviral envelope syncytin genes is required for formation of the two-layered murine placental syncytiotrophoblast. Proceedings of the National Academy of Sciences of the United States of America 2011, 108, E1164-1173, doi:10.1073/pnas.1112304108.

130. Tittarelli, A.; Navarrete, M.; Gleisner, M.A.; Gebicke-Haerter, P.; Salazar-Onfray, F. Connexin-Mediated Signaling at the Immunological Synapse. International journal of molecular sciences 2020, 21, doi:10.3390/ijms21103736.

131. Tittarelli, A. Connexin channels modulation in pathophysiology and treatment of immune and inflammatory disorders. Biochimica et biophysica acta. Molecular basis of disease 2021, 1867, 166258, doi:10.1016/j.bbadis.2021.166258.

132. Mendoza-Naranjo, A.; Bouma, G.; Pereda, C.; Ramírez, M.; Webb, K.F.; Tittarelli, A.; López, M.N.; Kalergis, A.M.; Thrasher, A.J.; Becker, D.L.; et al. Functional gap junctions accumulate at the immunological synapse and contribute to $T$ cell activation. Journal of immunology (Baltimore, Md. : 1950) 2011, 187, 3121-3132, doi:10.4049/jimmunol.1100378.

133. Tittarelli, A.; Mendoza-Naranjo, A.; Farías, M.; Guerrero, I.; Ihara, F.; Wennerberg, E.; Riquelme, S.; Gleisner, A.; Kalergis, A.; Lundqvist, A.; et al. Gap junction intercellular communications regulate NK cell activation and modulate NK cytotoxic capacity. Journal of immunology (Baltimore, Md. : 1950) 2014, 192, 1313-1319, doi:10.4049/jimmunol.1301297.

134. Benlalam, H.; Carré, T.; Jalil, A.; Noman, Z.; Caillou, B.; Vielh, P.; Tittarelli, A.; Robert, C.; Chouaib, S. Regulation of gap junctions in melanoma and their impact on Melan-A/MART-1-specific CD8 ${ }^{+}$T lymphocyte emergence. Journal of molecular medicine (Berlin, Germany) 2013, 91, 1207-1220, doi:10.1007/s00109-013-1058-5.

135. Hofmann, F.; Navarrete, M.; Álvarez, J.; Guerrero, I.; Gleisner, M.A.; Tittarelli, A.; Salazar-Onfray, F. Cx43-Gap Junctions Accumulate at the Cytotoxic Immunological Synapse Enabling Cytotoxic T Lymphocyte Melanoma Cell Killing. International journal of molecular sciences 2019, 20, doi:10.3390/ijms20184509.

136. Saccheri, F.; Pozzi, C.; Avogadri, F.; Barozzi, S.; Faretta, M.; Fusi, P.; Rescigno, M. Bacteria-induced gap junctions in tumors favor antigen cross-presentation and antitumor immunity. Science translational medicine 2010, 2, 44ra57, doi:10.1126/scitranslmed.3000739.

137. Benlalam, H.; Jalil, A.; Hasmim, M.; Pang, B.; Tamouza, R.; Mitterrand, M.; Godet, Y.; Lamerant, N.; Robert, C.; Avril, M.F.; et al. Gap junction communication between autologous endothelial and tumor cells induce cross-recognition and elimination by specific CTL. Journal of immunology (Baltimore, Md. : 1950) 2009, 182, 2654-2664, doi:10.4049/jimmunol.0800815. 
138. Manohar, M.; Hirsh, M.I.; Chen, Y.; Woehrle, T.; Karande, A.A.; Junger, W.G. ATP release and autocrine signaling through $\mathrm{P} 2 \mathrm{X} 4$ receptors regulate $\mathrm{y} \delta \mathrm{T}$ cell activation. Journal of leukocyte biology 2012, 92, 787-794, doi:10.1189/jlb.0312121.

139. Lee, H.Y.; Cha, J.; Kim, S.K.; Park, J.H.; Song, K.H.; Kim, P.; Kim, M.Y. c-MYC Drives Breast Cancer Metastasis to the Brain, but Promotes Synthetic Lethality with TRAIL. Molecular cancer research : MCR 2019, 17, 544-554, doi:10.1158/15417786.mcr-18-0630.

140. Balla, P.; Maros, M.E.; Barna, G.; Antal, I.; Papp, G.; Sapi, Z.; Athanasou, N.A.; Benassi, M.S.; Picci, P.; Krenacs, T. Prognostic impact of reduced connexin43 expression and gap junction coupling of neoplastic stromal cells in giant cell tumor of bone. PloS one 2015, 10, e0125316-e0125316, doi:10.1371/journal.pone.0125316.

141. Tittarelli, A.; Navarrete, M.; Lizana, M.; Hofmann-Vega, F.; Salazar-Onfray, F. Hypoxic Melanoma Cells Deliver microRNAs to Dendritic Cells and Cytotoxic T Lymphocytes through Connexin-43 Channels. International journal of molecular sciences 2020, 21, doi:10.3390/ijms21207567.

142. Tittarelli, A.; Janji, B.; Van Moer, K.; Noman, M.Z.; Chouaib, S. The Selective Degradation of Synaptic Connexin 43 Protein by Hypoxia-induced Autophagy Impairs Natural Killer Cell-mediated Tumor Cell Killing. The Journal of biological chemistry 2015, 290, 23670-23679, doi:10.1074/jbc.M115.651547.

143. Avanzo, J.L.; Mesnil, M.; Hernandez-Blazquez, F.J.; Mackowiak, II; Mori, C.M.; da Silva, T.C.; Oloris, S.C.; Gárate, A.P.; Massironi, S.M.; Yamasaki, H.; et al. Increased susceptibility to urethane-induced lung tumors in mice with decreased expression of connexin43. Carcinogenesis 2004, 25, 1973-1982, doi:10.1093/carcin/bgh193.

144. de Oliveira, K.D.; Tedardi, M.V.; Cogliati, B.; Dagli, M.L.Z. Higher incidence of lung adenocarcinomas induced by DMBA in connexin 43 heterozygous knockout mice. BioMed research international 2013, 2013, 618475-618475, doi:10.1155/2013/618475.

145. Evert, M.; Ott, T.; Temme, A.; Willecke, K.; Dombrowski, F. Morphology and morphometric investigation of hepatocellular preneoplastic lesions and neoplasms in connexin32-deficient mice. Carcinogenesis 2002, 23, 697-703, doi:10.1093/carcin/23.5.697.

146. King, T.J.; Lampe, P.D. Mice deficient for the gap junction protein Connexin32 exhibit increased radiation-induced tumorigenesis associated with elevated mitogenactivated protein kinase (p44/Erk1, p42/Erk2) activation. Carcinogenesis 2004, 25, 669680, doi:10.1093/carcin/bgh071.

147. Huang, L.; Guo, Y.; Cao, D.; Liu, X.; Zhang, L.; Cao, K.; Hu, T.; Qi, Y.; Xu, C. Effects of Helicobacter pylori on the expression levels of GATA-3 and connexin 32 and the GJIC function in gastric epithelial cells and their association by promoter analysis. Oncology letters 2018, 16, 1650-1658, doi:10.3892/ol.2018.8796.

148. Li, H.; Xu, C.X.; Gong, R.J.; Chi, J.S.; Liu, P.; Liu, X.M. How does Helicobacter pylori cause gastric cancer through connexins: An opinion review. World journal of gastroenterology 2019, 25, 5220-5232, doi:10.3748/wjg.v25.i35.5220.

149. Kim, E.M.; Bae, Y.M.; Choi, M.H.; Hong, S.T. Connexin 43 plays an important role in the transformation of cholangiocytes with Clonochis sinensis excretory-secretory 
protein and N-nitrosodimethylamine. PLoS neglected tropical diseases 2019, 13, e0006843, doi:10.1371/journal.pntd.0006843.

150. Naiki-Ito, A.; Kato, H.; Naiki, T.; Yeewa, R.; Aoyama, Y.; Nagayasu, Y.; Suzuki, S.; Inaguma, S.; Takahashi, S. A novel model of non-alcoholic steatohepatitis with fibrosis and carcinogenesis in connexin 32 dominant-negative transgenic rats. Archives of toxicology 2020, 94, 4085-4097, doi:10.1007/s00204-020-02873-5.

151. Ruch, R.J.; Trosko, J.E. The role of oval cells and gap junctional intercellular communication in hepatocarcinogenesis. Anticancer research 1999, 19, 4831-4838.

152. Liu, Y.; Deguchi, Y.; Tian, R.; Wei, D.; Wu, L.; Chen, W.; Xu, W.; Xu, M.; Liu, F.; Gao, S.; et al. Pleiotropic Effects of PPARD Accelerate Colorectal Tumorigenesis, Progression, and Invasion. Cancer research 2019, 79, 954-969, doi:10.1158/00085472.can-18-1790.

153. Adak, A.; Unal, Y.C.; Yucel, S.; Vural, Z.; Turan, F.B.; Yalcin-Ozuysal, O.; Ozcivici, E.; Mese, G. Connexin 32 induces pro-tumorigenic features in MCF10A normal breast cells and MDA-MB-231 metastatic breast cancer cells. Biochimica et biophysica acta. Molecular cell research 2020, 1867, 118851, doi:10.1016/j.bbamcr.2020.118851.

154. Dunn, C.A.; Lampe, P.D. Injury-triggered Akt phosphorylation of Cx43: a ZO-1driven molecular switch that regulates gap junction size. Journal of cell science 2014, 127, 455-464, doi:10.1242/jcs.142497.

155. Banerjee, D.; Gakhar, G.; Madgwick, D.; Hurt, A.; Takemoto, D.; Nguyen, T.A. A novel role of gap junction connexin46 protein to protect breast tumors from hypoxia. International journal of cancer 2010, 127, 839-848, doi:10.1002/ijc.25107.

156. Haass, N.K.; Ripperger, D.; Wladykowski, E.; Dawson, P.; Gimotty, P.A.; Blome, C.; Fischer, F.; Schmage, P.; Moll, I.; Brandner, J.M. Melanoma progression exhibits a significant impact on connexin expression patterns in the epidermal tumor microenvironment. Histochemistry and cell biology 2010, 133, 113-124, doi:10.1007/s00418-009-0654-5.

157. Bache, M.; Kappler, M.; Said, H.M.; Staab, A.; Vordermark, D. Detection and specific targeting of hypoxic regions within solid tumors: current preclinical and clinical strategies. Current medicinal chemistry 2008, 15, 322-338, doi:10.2174/092986708783497391.

158. Walsh, J.C.; Lebedev, A.; Aten, E.; Madsen, K.; Marciano, L.; Kolb, H.C. The clinical importance of assessing tumor hypoxia: relationship of tumor hypoxia to prognosis and therapeutic opportunities. Antioxidants \& redox signaling 2014, 21, 1516-1554, doi:10.1089/ars.2013.5378.

159. Orlova, A.G.; Kirillin, M.Y.; Volovetsky, A.B.; Shilyagina, N.Y.; Sergeeva, E.A.; Golubiatnikov, G.Y.; Turchin, I.V. Diffuse optical spectroscopy monitoring of oxygen state and hemoglobin concentration during SKBR-3 tumor model growth. Laser Physics Letters 2016, 14, 015601, doi:10.1088/1612-202x/aa4fc1.

160. Dovmark, T.H.; Hulikova, A.; Niederer, S.A.; Vaughan-Jones, R.D.; Swietach, P. Normoxic cells remotely regulate the acid-base balance of cells at the hypoxic core of connexin-coupled tumor growths. FASEB journal : official publication of the Federation of 
American Societies for Experimental Biology 2018, 32, 83-96, doi:10.1096/fj.201700480R.

161. Dovmark, T.H.; Saccomano, M.; Hulikova, A.; Alves, F.; Swietach, P. Connexin-43 channels are a pathway for discharging lactate from glycolytic pancreatic ductal adenocarcinoma cells. Oncogene 2017, 36, 4538-4550, doi:10.1038/onc.2017.71.

162. Hulikova, A.; Black, N.; Hsia, L.T.; Wilding, J.; Bodmer, W.F.; Swietach, P. Stromal uptake and transmission of acid is a pathway for venting cancer cell-generated acid. Proceedings of the National Academy of Sciences of the United States of America 2016, 113, E5344-5353, doi:10.1073/pnas.1610954113.

163. Kucheryavykh, L.Y.; Benedikt, J.; Cubano, L.A.; Skatchkov, S.N.; Bukauskas, F.F.; Kucheryavykh, Y.V. Polyamines preserve connexin 43-mediated gap junctional communication during intracellular hypercalcemia and acidosis. Neuroreport 2017, 28, 208-213, doi:10.1097/wnr.0000000000000746.

164. Mikuła-Pietrasik, J.; Uruski, P.; Szubert, S.; Maksin, K.; Moszyński, R.; Szpurek, D.; Woźniak, A.; Sajdak, S.; Tykarski, A.; Książek, K. The Proangiogenic Capabilities of Malignant Ascites Generated by Aggressive Ovarian Tumors. BioMed research international 2017, 2017, 2592496, doi:10.1155/2017/2592496.

165. Nagy, J.A.; Benjamin, L.; Zeng, H.; Dvorak, A.M.; Dvorak, H.F. Vascular permeability, vascular hyperpermeability and angiogenesis. Angiogenesis 2008, 11, 109119, doi:10.1007/s10456-008-9099-z.

166. Hao, H.; Gabbiani, G.; Bochaton-Piallat, M.L. Arterial smooth muscle cell heterogeneity: implications for atherosclerosis and restenosis development. Arteriosclerosis, thrombosis, and vascular biology 2003, 23, 1510-1520, doi:10.1161/01.atv.0000090130.85752.ed.

167. Elzarrad, K.; Haroon, A.; Reed, D.; Al-Mehdi, A.B. Early incorporated endothelial cells as origin of metastatic tumor vasculogenesis. Clinical \& experimental metastasis 2009, 26, 589-598, doi:10.1007/s10585-009-9257-8.

168. Wang, W.K.; Chen, M.C.; Leong, H.F.; Kuo, Y.L.; Kuo, C.Y.; Lee, C.H. Connexin 43 suppresses tumor angiogenesis by down-regulation of vascular endothelial growth factor via hypoxic-induced factor-1 $\alpha$. International journal of molecular sciences 2014,16 , 439-451, doi:10.3390/ijms16010439.

169. Zibara, K.; Awada, Z.; Dib, L.; El-Saghir, J.; Al-Ghadban, S.; Ibrik, A.; El-Zein, N.; El-Sabban, M. Anti-angiogenesis therapy and gap junction inhibition reduce MDA-MB231 breast cancer cell invasion and metastasis in vitro and in vivo. Sci Rep 2015, 5, 12598, doi:10.1038/srep12598.

170. Crespin, S.; Fromont, G.; Wager, M.; Levillain, P.; Cronier, L.; Monvoisin, A.; Defamie, N.; Mesnil, M. Expression of a gap junction protein, connexin43, in a large panel of human gliomas: new insights. Cancer medicine 2016, 5, 1742-1752, doi:10.1002/cam4.730.

171. Kutova, O.M.; Pospelov, A.D.; Krylova, L.V.; Gorshkova, E.N.; Balalaeva, I.V. Adhesion Proteins Profile and Localization in Ovarian Carcinoma Cell Lines. Opera Medica et Physiologica 2021, 8, 12, doi:10.24412/2500-2295-2021-2-43-54. 
172. Navarrete, M.; Salazar-Onfray, F.; Tittarelli, A. Flow Cytometry Evaluation of Gap Junction-Mediated Intercellular Communication Between Cytotoxic T Cells and Target Tumor Cells. Methods in molecular biology (Clifton, N.J.) 2021, 2346, 225-236, doi:10.1007/7651_2020_326.

173. Li, G.; Liu, X.; Liu, Z.; Su, Z. Interactions of connexin 43 and aquaporin-4 in the formation of glioma-induced brain edema. Molecular medicine reports 2015, 11, 11881194, doi:10.3892/mmr.2014.2867.

174. Ehrlich, A.; Molica, F.; Hautefort, A.; Kwak, B.R. Lymphatic Connexins and Pannexins in Health and Disease. International journal of molecular sciences 2021, 22, doi:10.3390/ijms22115734.

175. Thuringer, D.; Jego, G.; Berthenet, K.; Hammann, A.; Solary, E.; Garrido, C. Gap junction-mediated transfer of miR-145-5p from microvascular endothelial cells to colon cancer cells inhibits angiogenesis. Oncotarget 2016, 7, 28160-28168, doi:10.18632/oncotarget.8583.

176. Fukuda, S.; Akiyama, M.; Niki, Y.; Kawatsura, R.; Harada, H.; Nakahama, K.I. Inhibitory effects of miRNAs in astrocytes on $\mathrm{C} 6$ glioma progression via connexin 43. Molecular and cellular biochemistry 2021, 476, 2623-2632, doi:10.1007/s11010-02104118-0.

177. Hong, X.; Sin, W.C.; Harris, A.L.; Naus, C.C. Gap junctions modulate glioma invasion by direct transfer of microRNA. Oncotarget 2015, 6, 15566-15577, doi:10.18632/oncotarget.3904.

178. Zong, L.; Zhu, Y.; Liang, R.; Zhao, H.B. Gap junction mediated miRNA intercellular transfer and gene regulation: A novel mechanism for intercellular genetic communication. Sci Rep 2016, 6, 19884, doi:10.1038/srep19884.

179. Peng, Y.; Wang, X.; Guo, Y.; Peng, F.; Zheng, N.; He, B.; Ge, H.; Tao, L.; Wang, Q. Pattern of cell-to-cell transfer of microRNA by gap junction and its effect on the proliferation of glioma cells. Cancer science 2019, 110, 1947-1958, doi:10.1111/cas.14029.

180. Prasad, S.; Ramachandran, S.; Gupta, N.; Kaushik, I.; Srivastava, S.K. Cancer cells stemness: A doorstep to targeted therapy. Biochimica et Biophysica Acta (BBA) Molecular Basis of Disease 2020, 1866, 165424, doi:https://doi.org/10.1016/j.bbadis.2019.02.019.

181. Shen, Y.; Li, Y.; Ma, X.; Wan, Q.; Jiang, Z.; Liu, Y.; Zhang, D.; Liu, X.; Wu, W. Connexin 43 SUMOylation improves gap junction functions between liver cancer stem cells and enhances their sensitivity to HSVtk/GCV. International journal of oncology 2018, 52, 872-880, doi:10.3892/ijo.2018.4263.

182. Ruch, R.J. Connexin43 Suppresses Lung Cancer Stem Cells. Cancers 2019, 11, doi:10.3390/cancers11020175.

183. Arun, S.; Ravisankar, S.; Vanisree, A.J. Implication of connexin30 on the stemness of glioma: connexin30 reverses the malignant phenotype of glioma by modulating IGF$1 \mathrm{R}, \mathrm{CD} 133$ and cMyc. Journal of neuro-oncology 2017, 135, 473-485, doi:10.1007/s11060-017-2608-4. 
184. Patel, S.A.; Dave, M.A.; Bliss, S.A.; Giec-Ujda, A.B.; Bryan, M.; Pliner, L.F.; Rameshwar, P. T(reg)/Th17 polarization by distinct subsets of breast cancer cells is dictated by the interaction with mesenchymal stem cells. Journal of cancer stem cell research 2014, 2014, doi:10.14343/JCSCR.2014.2e1003.

185. Sinha, G.; Ferrer, A.I.; Ayer, S.; El-Far, M.H.; Pamarthi, S.H.; Naaldijk, Y.; Barak, P.; Sandiford, O.A.; Bibber, B.M.; Yehia, G.; et al. Specific N-cadherin-dependent pathways drive human breast cancer dormancy in bone marrow. Life science alliance 2021, 4, doi:10.26508/lsa.202000969.

186. Kuramoto, K.; Yamamoto, M.; Suzuki, S.; Sanomachi, T.; Togashi, K.; Seino, S.; Kitanaka, C.; Okada, M. AS602801, an Anti-Cancer Stem Cell Drug Candidate, Suppresses Gap-junction Communication Between Lung Cancer Stem Cells and Astrocytes. Anticancer research 2018, 38, 5093-5099, doi:10.21873/anticanres.12829.

187. Liu, Y.; Pandey, P.R.; Sharma, S.; Xing, F.; Wu, K.; Chittiboyina, A.; Wu, S.Y.; Tyagi, A.; Watabe, K. ID2 and GJB2 promote early-stage breast cancer progression by regulating cancer stemness. Breast cancer research and treatment 2019, 175, 77-90, doi:10.1007/s10549-018-05126-3.

188. Kawasaki, Y.; Omori, Y.; Li, Q.; Nishikawa, Y.; Yoshioka, T.; Yoshida, M.; Ishikawa, K.; Enomoto, K. Cytoplasmic accumulation of connexin32 expands cancer stem cell population in human $\mathrm{HuH} 7$ hepatoma cells by enhancing its self-renewal. International journal of cancer 2011, 128, 51-62, doi:10.1002/ijc.25308.

189. Acuña, R.A.; Varas-Godoy, M.; Herrera-Sepulveda, D.; Retamal, M.A. Connexin46 Expression Enhances Cancer Stem Cell and Epithelial-to-Mesenchymal Transition Characteristics of Human Breast Cancer MCF-7 Cells. International journal of molecular sciences 2021, 22, doi:10.3390/ijms222212604.

190. Trosko, J.E. Cancer Prevention and Therapy of Two Types of Gap Junctional Intercellular Communication-Deficient "Cancer Stem Cell". Cancers 2019, 11, 87, doi:10.3390/cancers 11010087 .

191. Trosko, J.E. On the potential origin and characteristics of cancer stem cells. Carcinogenesis 2021, 42, 905-912, doi:10.1093/carcin/bgab042.

192. Trosko, J.E. In Search of a Unifying Concept in Human Diseases. Diseases 2021, 9,68 .

193. Sokolova, E.A.; Vodeneev, V.A.; Deyev, S.M.; Balalaeva, I.V. 3D in vitro models of tumors expressing EGFR family receptors: a potent tool for studying receptor biology and targeted drug development. Drug discovery today 2019, 24, 99-111, doi:10.1016/j.drudis.2018.09.003.

194. Pospelov, A.D.; L.B., T.; Cherkasova, E.I.; Balalaeva, I.V. Comparative Analysis of Two Protocols of Mouse Tissues Decellularization for Application in Experimental Oncology. Opera Medica et Physiologica 2020, 7, 13-21, doi:10.24411/2500-2295-202010010.

195. Dornhof, J.; Kieninger, J.; Muralidharan, H.; Maurer, J.; Urban, G.A.; Weltin, A. Microfluidic organ-on-chip system for multi-analyte monitoring of metabolites in $3 \mathrm{D}$ cell cultures. Lab on a chip 2021, doi:10.1039/d1lc00689d. 
196. Mendoza-Martinez, A.K.; Loessner, D.; Mata, A.; Azevedo, H.S. Modeling the Tumor Microenvironment of Ovarian Cancer: The Application of Self-Assembling Biomaterials. Cancers 2021, 13, doi:10.3390/cancers13225745.

197. Sankarasubramanian, S.; Pfohl, U.; Regenbrecht, C.R.A.; Reinhard, C.; Wedeken, L. Context Matters-Why We Need to Change From a One Size Fits all Approach to Madeto-Measure Therapies for Individual Patients With Pancreatic Cancer. Frontiers in cell and developmental biology 2021, 9, 760705, doi:10.3389/fcell.2021.760705.

198. Yu, J.; Boicea, A.; Barrett, K.L.; James, C.O.; Bagchi, I.C.; Bagchi, M.K.; Nezhat, C.; Sidell, N.; Taylor, R.N. Reduced connexin 43 in eutopic endometrium and cultured endometrial stromal cells from subjects with endometriosis. Molecular human reproduction 2014, 20, 260-270, doi:10.1093/molehr/gat087.

199. Neveu, M.J.; Sattler, C.A.; Sattler, G.L.; Hully, J.R.; Hertzberg, E.L.; Paul, D.L.; Nicholson, B.J.; Pitot, H.C. Differences in the expression of connexin genes in rat hepatomas in vivo and in vitro. Molecular carcinogenesis 1994, 11, 145-154, doi:10.1002/mc.2940110305.

200. Kutova, O.M.; Sencha, L.M.; Pospelov, A.D.; Dobrynina, O.E.; Brilkina, A.A.; Cherkasova, E.I.; Balalaeva, I.V. Comparative Analysis of Cell-Cell Contact Abundance in Ovarian Carcinoma Cells Cultured in Two- and Three-Dimensional In Vitro Models. Biology 2020, 9, doi:10.3390/biology9120446.

201. Tawfik, D.; Zaccagnino, A.; Bernt, A.; Szczepanowski, M.; Klapper, W.; Schwab, A.; Kalthoff, H.; Trauzold, A. The A818-6 system as an in-vitro model for studying the role of the transportome in pancreatic cancer. BMC cancer 2020, 20, 264, doi:10.1186/s12885-020-06773-w.

202. Orlando-Mathur, C.E.; Bechberger, J.F.; Goldberg, G.S.; Naus, C.C.; Kidder, G.M.; Kennedy, T.G. Rat endometrial stromal cells express the gap junction genes connexins 26 and 43 and form functional gap junctions during in vitro decidualization. Biology of reproduction 1996, 54, 905-913, doi:10.1095/biolreprod54.4.905.

203. Bonacquisti, E.E.; Nguyen, J. Connexin 43 (Cx43) in cancer: Implications for therapeutic approaches via gap junctions. Cancer letters 2019, 442, 439-444, doi:10.1016/j.canlet.2018.10.043.

204. Jindal, S.; Chockalingam, S.; Ghosh, S.S.; Packirisamy, G. Connexin and gap junctions: perspectives from biology to nanotechnology based therapeutics. Translational research : the journal of laboratory and clinical medicine 2021, 235, 144-167, doi:10.1016/j.trsl.2021.02.008.

205. Nalewajska, M.; Marchelek-Myśliwiec, M.; Opara-Bajerowicz, M.; Dziedziejko, V.; Pawlik, A. Connexins-Therapeutic Targets in Cancers. International journal of molecular sciences 2020, 21, doi:10.3390/ijms21239119. 